\title{
THE USE OF TWO-DIODE SUBSTITUTE MODEL IN PREDICTING THE EFFICIENCY OF PV CONVERSION IN LOW SOLAR CONDITIONS
}

\author{
UŻYCIE DWUDIODOWEGO MODELU ZASTĘPCZEGO \\ W PROGNOZOWANIU EFEKTYWNOŚCI KONWERSJI PV \\ W WARUNKACH NISKICH NASŁONECZNIEŃ
}

\begin{abstract}
The article presents theoretical foundations of a two-diode equivalent model of a photovoltaic cell/module (PV), together with calculation procedures. A physical interpretation of individual components of an equivalent model was presented. Its practical application in predicting efficiency of operation of various PV cells and modules in low insulation conditions was demonstrated. The obtained predictions were verified with the actual results of their operation in open space (outdoor). The practical suitability of the "model" in early detection of ageing phenomena, such as, for example, absorber degradation taking place in PV modules, was demonstrated. The article was prepared on the basis of the results of testing five different PV modules with various constructions, made of different materials and absorbers, such as: c-Si, mc-Si, CIS, a-Si_SJ, a-Si_TJ. The used measurement data were collected during the 16-year period of the experimental PV modules testing system operation in University of Opole, equipped with a data acquisition system.
\end{abstract}

Keywords: photovoltaic conversion, PV cells quality assessment, PV modules quality assessment, PV cells degradation, PV modules degradation, PV conversion sensitivity, determining two-diode equivalent model

This article is the first in a series of two articles dealing with the non-standard use of widely known models and computational procedures in PV metering. It concerns the non-standard use of the two-diode model to assess the quality of work, including suitability for very low and low solar conditions, and easy assessment of cell and PV modules degradation. The second one - concerns the use of standardized Blazer characteristic to assess the structural and material degradation of cells and modules under medium and high solar conditions. The above articles were written as a guide for the aforementioned research, with very extensive details of some leads and comments.

\footnotetext{
${ }^{1}$ Division of of Bioanalysis, Chair of Biotechnology and Molecular Biology, University of Opole, ul. kard. B. Kominka 6, 45-032 Opole, Poland, phone +48 7745389 76, +48 7740160 42, fax +48 774559149 , email: maria.waclawek@uni.opole.pl,mrajfur@o2.pl

*Corresponding author: trodziewicz@wp.pl
} 


\section{Introduction}

\section{Dark current-voltage characteristics of a cell}

Dark current-voltage characteristics of a cell, i.e. the characteristics of a cell in the dark is obtained by drawing a cell current intensity in the function of the value of the cell polarisation voltage, in the current forward bias. For an ideal cell, with only one mechanism of the dark current generation - injection of majority charge carriers above energy barriers, intensity of dark current $I_{D}$ in the voltage function is described by the Shockley diode equation, referring to the diffusive mechanism of the charge carriers flow [1-3]:

$$
I_{D}=I_{S}\left(\exp \frac{q U}{k_{B} T}-1\right)
$$

where: $I_{S}$ - diffusion saturation current of dark current carriers flow; $U$ - polarisation voltage of a cell junction; $\varphi_{T}=k_{B} T / q$ - free enthalpy (thermodynamic potential) for silicon, of $26 \mathrm{mV}$ at temperature of $300 \mathrm{~K} ; k_{B}$ - Boltzmann constant; $T$ - temperature; $q$ - elementary charge.

However, there are also other mechanisms of the majority carriers transport in real $n-p$ and $p-n$ cells, namely: recombination in the surface depleted region and multi-level tunnelling via energy status in the energy gap, resulting from defects in the crystalline structure. Thus, the total dark current of a real cell $\left(I_{\text {dark }}\right)$ is a sum of two components (2): $I_{01}$ - recombination component from quasi-neutral regions ( $\mathrm{n}$ and $\mathrm{p}$ ) - including the diffusion mechanism of carriers flow, together with the surface regions recombination current [4] and $I_{02}$ - generation-recombination component of space charge region [5-8]:

$$
\begin{gathered}
I_{\text {dark }}=I_{01}+I_{02} \\
I_{\text {dark }}=I_{S 1}\left(\exp \frac{q U}{k_{B} T}-1\right)+I_{S 2}\left(\exp \frac{q U}{2 k_{B} T}-1\right),
\end{gathered}
$$

where: $I_{S 1}, I_{S 2}$ - is the dark current of recombination saturation, respectively: in quasi-neutral regions ( $\mathrm{n}$ and $\mathrm{p}$ ) and from recombination in space charge region.

The components in the formula (3) represent two parallel connected diodes and the resulting characteristics is the sum of their characteristics (adding currents). The formula is the basis of the two-diode model (diagram) of an equivalent PV cell, in which the cell junction is modelled by parallel connected two diodes, described by $I-U$ characteristics. Note that the two-diode model (3) does not contain any ohmic shunt resistance $R_{p}$ nor a series resistance $R_{S}$. It is common practice to include also these entities in a one- or two-diode model via an equivalent circuit $[9,10]$ :

$$
I=I_{S 1}\left(\exp \frac{q\left(U-I R_{S}\right)}{k_{B} T}-1\right)+I_{S 2}\left(\exp \frac{q\left(U-I R_{S}\right)}{2 k_{B} T}-1\right)+\frac{U-I R_{S}}{R_{s h}},
$$

Figure 1 presents an example of dark current-voltage characteristics of one of the analysed PV cells, which graphic format was obtained from [11]: After drawing the characteristics in a coordinate system, where the current axis $(I[\mathrm{~A}])$ has logarithmic scale and voltage axis $(U[\mathrm{~V}])$ is linear (i.e. application of the log-lin coordinates system), the graph $\log I=\mathrm{f}(U)$ is obtained, as in Figure 1. Characteristics of dark current of a real cell (4), taking into consideration the recombination current from quasi-neutral regions $\left(I_{01}\right)$ and 
from the space charge region $\left(I_{02}\right)$ is a curve with two straight-line sections, in this system of coordinates. The first section with inclination $q U / 2 k_{B} T$ is in the region of domination $I_{02}$ of dark current and is limited from the left by the curve caused by the occurrence of leakage resistance $R_{s h}$. The second section with inclination $q U / k_{B} T$ is in the region of domination $I_{01}$, which is limited from the right by the curve, caused by the voltage drop in semiconductor resistance from the outside of the spatial charge region and drop of voltage in other cell construction elements (e.g. electrodes, connections, etc.), conventionally referred to as the voltage drop in so called serial resistance of a cell $\left(R_{S}\right)$, which can be detected in large currents range $\left(\Delta U=I \cdot R_{S}\right)$.

By extrapolation of the above mentioned linear parts of characteristics to the current axis (reading for $U=0$ ), it is easy to read in the coordinates system log-lin, the values of both saturation currents; in the analysed case they amounted to $I_{S 2} \approx 7 \mathrm{~mA}$ and $I_{S 1} \approx 56 \mu \mathrm{A}$.

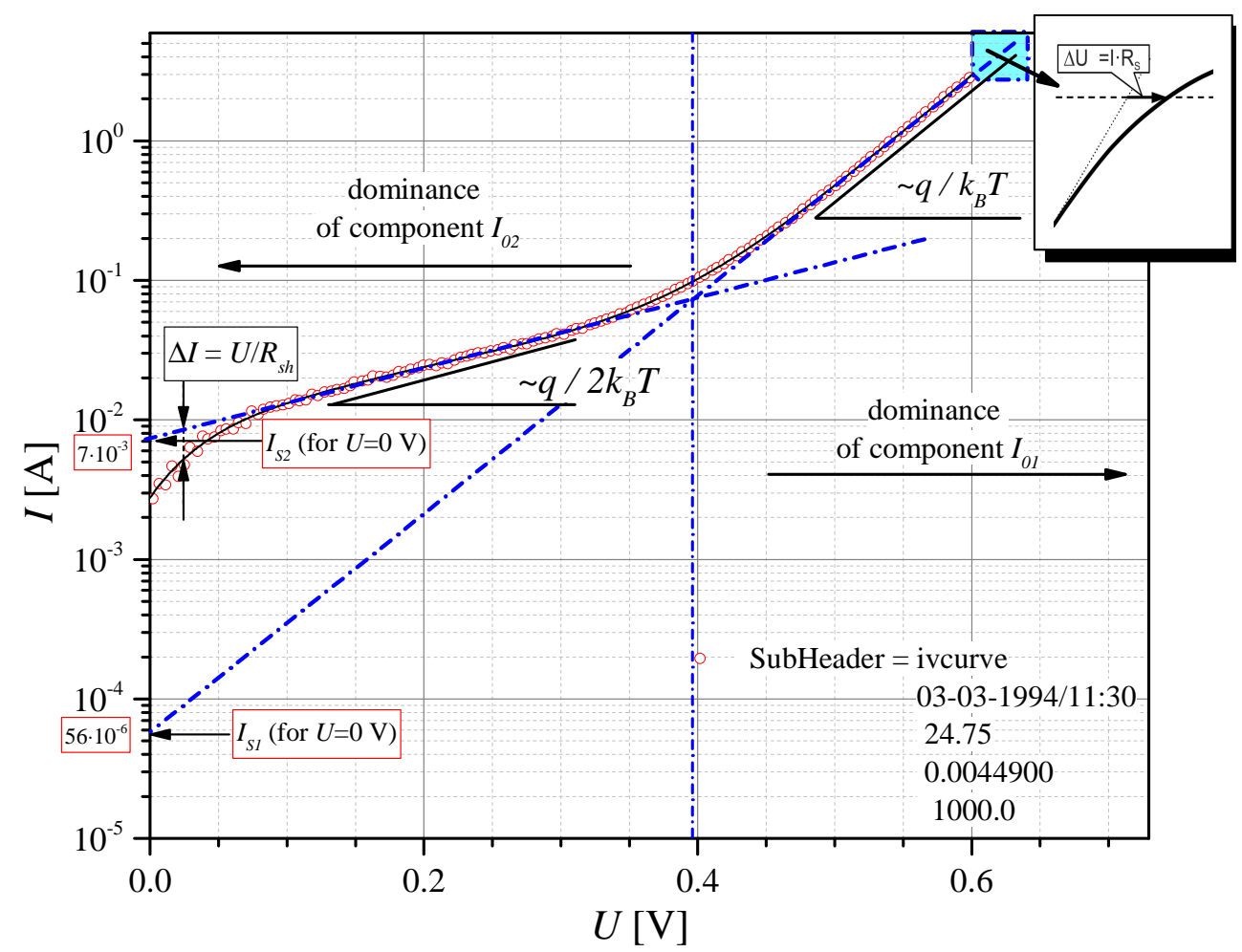

Fig. 1. Current-voltage characteristics of dark current of a PV cell, in line with [11], with marked current components domination regions

\section{PV cell equivalent models}

Regarding electric characteristics and taking into consideration parasitic resistances of junction leakage current and serial resistance, a solar cell can be substituted with an equivalent circuit presented in Figure 2. 


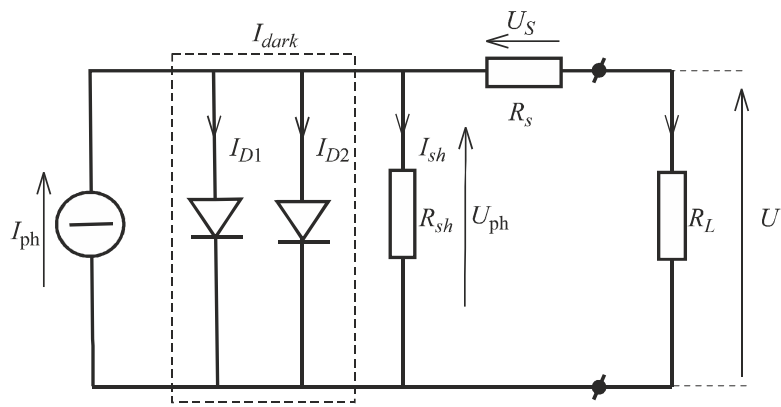

Fig. 2. An equivalent system of a silicon solar cell

Figure 2 presents a two-diode equivalent model of a solar cell, considering parasitic resistance of leakage current $R_{s h}$ and serial resistance $R_{S}$. In line with Kirchhoff's law, a relation between current and voltage in a photovoltaic cell is obtained [12]:

$$
I=I_{p h}-I_{d a r k}-\frac{U+R_{S} \cdot I}{R_{s h}},
$$

for a two-diode model [12-14]:

$$
\begin{gathered}
I_{d a r k}=I_{D 1}+I_{D 2} \\
I_{D 1}=I_{S 1} \cdot\left\{\exp \frac{q\left(U+R_{S} \cdot I\right)}{k_{B} T}-1\right\}, \\
I_{D 2}=I_{S 2} \cdot\left\{\exp \frac{q\left(U+R_{S} \cdot I\right)}{2 \cdot k_{B} T}-1\right\},
\end{gathered}
$$

for a one-diode model [12-14]:

$$
I_{\text {dark }}=I_{0} \cdot\left\{\exp \frac{q\left(U+R_{S} \cdot I\right)}{m \cdot k_{B} T}-1\right\},
$$

where: $I_{D 1}$-intensity of the recombination component of dark current from quasi-neutral regions ( $\mathrm{n}$ and $\mathrm{p}$ ); $I_{D 2}$ - intensity of the recombination component of dark current from space charge region; $I_{S 1}, I_{S 2}$ - dark current of recombination saturation, respectively: from quasi-neutral regions ( $\mathrm{n}$ and $\mathrm{p}$ ) and space charge region, determined, for example, by graphical method through interpolation of the curves from Figure $1 ; I_{0}$ - value of saturation current in a one-day model; $q$ - elementary charge; $R_{S}$ - serial resistance; $R_{\text {sh }}$ - leakage resistance; $R_{L}$ - load resistance; $k_{B}$ - Boltzmann constant; m - coefficient of a diode quality in a one-diode model - a dimensionless value defining the degree of adjustment of a photovoltaic cell to an ideal diode model, indicating the proportion of $I_{01}$ and $I_{02}$ current in dark current. For good quality cells, the value is usually 1-2. In the case of prevailing current of recombination component from quasi-neutral regions (n and p) $\left(I_{01}\right)$ the value of coefficient $m \cong 1$. In the case of prevailing generation-recombination current of space charge region $\left(I_{02}\right)$, then coefficient $m \cong 2[15]$. 
A connector excellence coefficient is determined by solving the following set of equations (assuming that $U_{1}-U_{2}$ is the change of voltage with the change of current, i.e. for $x=10$ or 0.1$)$ :

$$
\begin{aligned}
& \left\{\begin{array}{c}
I_{1}=I_{0} e^{\frac{q U_{1}}{m k_{B} T}} \\
I_{2}=x \cdot I_{1}=I_{0} e^{\frac{q U_{2}}{m k_{B} T}},
\end{array}\right. \\
& m=\frac{q}{k_{B} T} \cdot \frac{U_{1}-U_{2}}{\ln \left(x^{-1}\right)},
\end{aligned}
$$

where $k_{B} T / q$ is free enthalpy (thermodynamic potential) for silicon, amounting to $26 \mathrm{mV}$ at temperature of $300 \mathrm{~K}$.

Considering that:

$$
\log a=(\log e) \cdot(\ln a)=0.434 \ln a
$$

Expression (10) takes a more usable form:

$$
m=0.434 \frac{q}{k_{B} T} \cdot \frac{U_{1}-U_{2}}{\log \left(x^{-1}\right)} .
$$

Frequently, the determined coefficient $m$ for certain commercial cells of lower quality exceeds 2 and has no constant value, which cannot be explained by the classical two-diode theory. It increases together with a cell load increase ${ }^{2}$ exceeding even 4 (e.g. measurement of dark characteristics $I-U$ of a cell with a large load current) [10]. This is caused by the presence of defect in crystalline structure, creating the so called "non-linear shunts" $R_{p}$, which are basically due to locally extended defects leading to a local recombination current. Concentration of non-linear shunts increases with increasing load, in particular when a cell (module) was previously under a continuous and large current flow ${ }^{3}$, hence with increasing local concentration of defect states) [10]. More information regarding the influence of absorber degradation on the value of $m$ coefficient can be found in [10, 14, 16-18].

Assuming that $U=0$ (then $I=I_{S C}$ ) and neglecting the components which include $I_{S 1}$ and $I_{S 2}$, which are very small in comparison with $I_{p h}$, one can obtain from (5) an interrelation for the approximate value of the short-circuit current (13):

$$
I_{S C} \approx \frac{I_{p h}}{1+\frac{R_{S}}{R_{s h}}} .
$$

In well made cells, for which $R_{S} / R_{s h}<<1$, it can be assumed that: $\mathrm{I}_{S C} \approx I_{p h}$.

Assuming that in the formula (5) $\mathrm{I}=0$, and $\mathrm{U}=U_{O C}$, the following interrelations for an open circuit voltage can be obtained:

- $\quad$ when the component $I_{01}$ dominates, i.e. recombination of quasi-neutral regions:

$$
U_{O C}=\frac{k_{B} T}{q} \cdot \ln \left(1+\frac{I_{S C}}{I_{S 1}}\right)
$$

\footnotetext{
${ }^{2}$ Load current of not illuminated cell is an external current - response to added voltage, e.g. during measurements of dark characteristics $I-U$ of a PV cell. At polarisation, in forward bias, it is dark current of a PV cell.

${ }^{3}$ e.g. for a non-illuminated cell: - by the connected in forward bias a strong, external current source, or a strongly illuminated cell - by the dark current in an open cell.
} 
- $\quad$ when the component $I_{02}$ dominates, i.e. recombination of space charge regions:

$$
U_{O C}=\frac{2 \cdot k_{B} T}{q} \cdot \ln \left(1+\frac{I_{S C}}{I_{S 2}}\right) .
$$

More details and descriptions of coefficients extractions can be found in [11, 19-23].

\section{PV modules equivalent models}

All the above mentioned interrelations referring to the PV equivalent cell model can be adapted in a simple way to the two-diode equivalent PV module models. In the case of a module built from serially connected $N$-identical PV cells, individual interrelations are as follows:

for a two-diode model:

$$
\begin{aligned}
& I_{D 1}=I_{S 1} \cdot\left\{\exp \frac{q\left(U+R_{S} \cdot I\right) / N}{k_{B} T}-1\right\}, \\
& I_{D 2}=I_{S 2} \cdot\left\{\exp \frac{q\left(U+R_{S} \cdot I\right) / N}{2 \cdot k_{B} T}-1\right\},
\end{aligned}
$$

for a one-diode model:

$$
I_{\text {dark }}=I_{0} \cdot\left\{\exp \frac{q\left(U+R_{S} \cdot I\right) / N}{m \cdot k_{B} T}-1\right\},
$$

for interrelation of voltage of an open circuit $U_{O C}$ :

- $\quad$ when the component $I_{01}$ dominates, i.e. recombination of quasi-neutral regions:

$$
U_{O C}=\frac{k_{B} T}{q} \cdot N \cdot \ln \left(1+\frac{I_{S C}}{I_{S 1}}\right)
$$

- $\quad$ when the component $I_{02}$ dominates, i.e. recombination of space charge region:

$$
U_{O C}=\frac{2 \cdot k_{B} T}{q} \cdot N \cdot \ln \left(1+\frac{I_{S C}}{I_{S 2}}\right)
$$

\section{Practical application of a two-diode model in PV cells and modules research}

According to the superposition principle, which applies in the range of small solar radiation intensity values and is fulfilled also for natural solar radiation [24], current-voltage characteristics $(I-U)$ of an illuminated PV cell/module is a result of shifting the reversed dark characteristics (i.e. of not illuminated cell/module) along the current axis, by the value photocurrent generated in it $\left(I_{p h}\right)$ (Fig. 3).

Thus it is the difference between photocurrent $\left(I_{p h}\right)$ and dark current $\left(I_{d a r k}\right)$ of a PV cell/module. Similarly, the dark characteristics can be obtained by deducting from photocurrent value $\left(I_{p h} \cong I_{S C}\right)$ its characteristics $I$ - $U$ :

$$
I_{\text {dark }}(U)=I_{p h}-I(U)
$$


In well made PV cells/modules, for which $R_{S} / R_{s h} \ll<1$, it can be assumed that: $I_{p h} \approx I_{S C}$.

$$
I_{\text {dark }}(U)=I_{S C}-I(U) \text {. }
$$
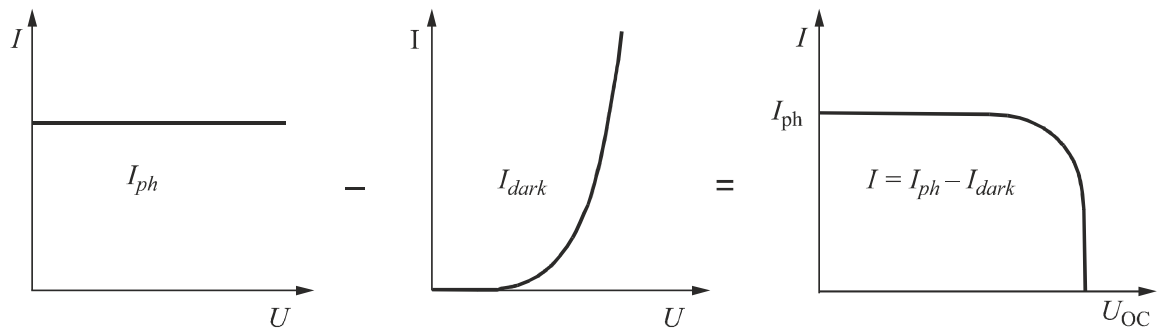

Fig. 3. Illuminated $I-U$ characteristics of a cell as the result of the difference between photocurrent and the value of the current from a cell dark characteristics [24, 25]
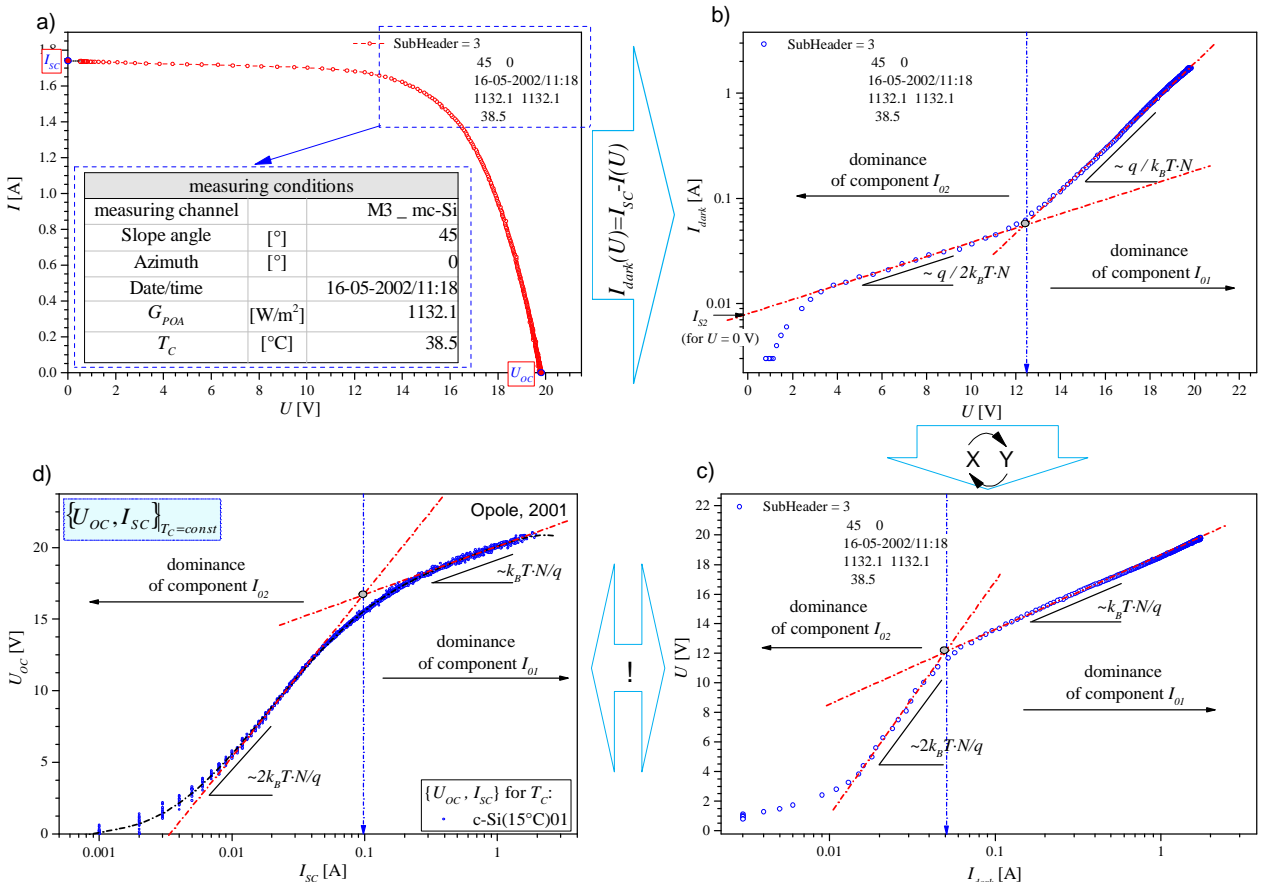

Fig. 4. Methodology of determination of dark characteristics $I-U$ of a PV object: a) registered illuminated characteristics $I-U$ of a PV module (in the table presented in figure a) there is a key to decoding the entries in headings of the registered PV modules characteristics); b) dark characteristics of a PV module, determined in line with (22) in the scale log-lin; c) dark characteristics of a PV module after rotating the coordinates axis $(X-Y)$; d) actual distribution of points with coordinates $\left(U_{O C}, I_{S C}\right)$ obtained for the constant value of temperature $T_{c}$ of the tested PV module

The relation (22) enables easy determination of dark current characteristics of the operating PV cell/module. It is not necessary to dismount a cell and transport it to 
a laboratory, in order to measure the current response to the forced voltage of not illuminated PV module. This is sufficient, in natural operation conditions, to register illuminated (i.e. not dark) $I-U$ characteristics of a cell/module, in the function of load change, i.e. from opening to closing i.e. short circuit.

Figure 4a,b presents a graph of an alternative methodology of determining dark characteristics of an operating PV module. Whereas Figure 4d presents a great convergence between characteristics of points $\left(U_{O C}, I_{S C}\right)$ distribution, obtained for the constant temperature value of the module junction/absorber $T_{C}$ (hereinafter referred to as module temperature $T_{C}$ ) and dark characteristics of the module, obtained after conversion of its coordinate axis (Fig. 4c).

The graph of the points $\left(U_{O C}, I_{S C}\right)$ distribution obtained for the constant value of temperature of the module $T_{C}$ (i.e. its approximation), presented in the coordinates system lin-log takes the form of a curve with two straight-line sections (Fig. 4d), the first with inclination $2 k_{B} T \cdot N / q$ and the second $-k_{B} T \cdot N / q$. Considering the relation (20) and (19), it can be noticed that distribution of points $\left(U_{O C}, I_{S C}\right)$ in the graph reflects the graph illustrating voltage of an open circuit $U_{O C}=\mathrm{f}\left(I_{S C}\right)$ for individual current regions $I_{S C}$, in which components of dark current dominate.

Thus, a conclusion can be drawn that the graph of distribution of points $\left(U_{O C}, I_{S C}\right)$ reflecting the flow of the $U_{O C}=\mathrm{f}\left(I_{S C}\right)$ function is a type of modification of the dark current graph from Fig. 4c). This modification has common features and considerable interpretation differences. The short-circuit current $I_{S C}$ of the illuminated module from Figure $4 \mathrm{~d}$, has almost equal value as photocurrent $\left(I_{p h} \approx I_{S C}\right)$. When the illuminated module is open, it is equal to the sum of components $I_{01}$ and $I_{02}$, for which the voltage on the terminals is $U_{O C}$. This current is an equivalent of the forced current ${ }^{4}$ from Figure $4 c$, for which a drop of voltage at module's terminals equal to $U=U_{O C}$, is obtained, of course for the same temperature of $T_{C}$ module. The change of the forced current value from Figure $4 \mathrm{~d}$ occurs through the change of the value of solar radiation intensity $G_{P O A}\left[\mathrm{~W} / \mathrm{m}^{2}\right]$, therefore it is necessary to carry out long-term outdoor research, so that the forced currents occurring at relevant PV module temperatures can be filtered out. The main interpretation difference is: characteristics of dark current from Figure 4b-c are momentary characteristics, obtained at a given moment for precisely defined laboratory conditions (all graph made in a specific moment), whereas the characteristics from Figure $4 \mathrm{~d}$ is an averaged graph for a defined period of time. The graph is made on the basis of long-term research, covering the period of several months, quarters or a year. Here, one measurement point $U_{O C}$ reflects one current value $I_{S C}$, which is obtained in the conditions of the defined intensity of radiation $G_{P O A}$ and the module temperature $T_{C}$. In such a graph, many components are averaged, such as, for example, the influence of the change of the solar radiation spectrum on operation of $P V$ modules, the influence of air mass change, short term ageing effects in modules and certain other atmospheric factors. The graph obtained in this way relates to the averaged conditions prevailing in the research location. Therefore, such graphs should be prepared taking into consideration their final location.

\footnotetext{
${ }^{4}$ After conversion of the coordinates axis, current becomes the forcing elements and the response is the voltage drop in PV module
} 


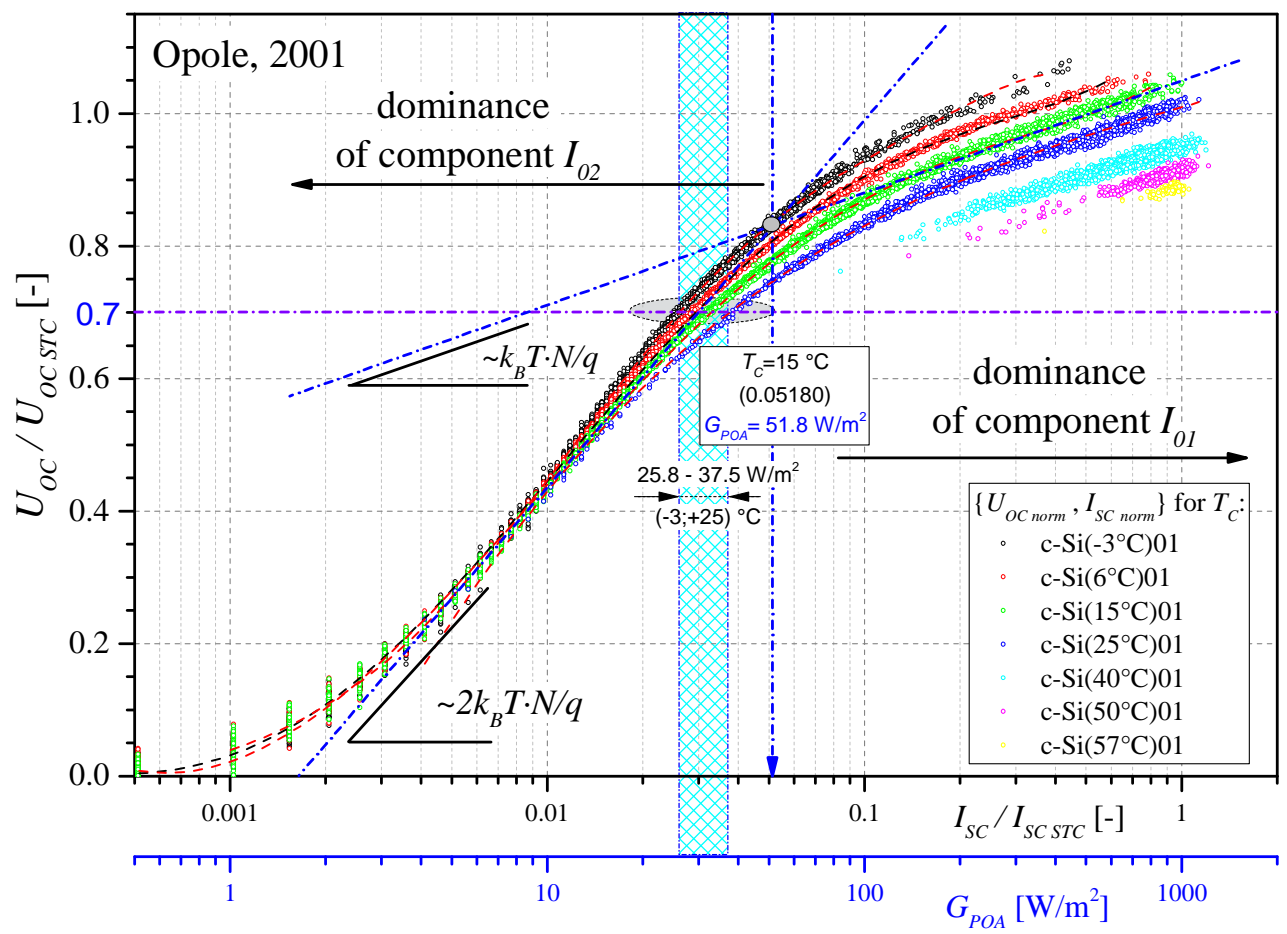

Fig. 5. Distribution of points $\left(U_{O C \text { norm }}, I_{S C \text { norm }}\right)$ for parametrically changing temperature of a PV module, as the graph $U_{O C \text { norm }}$ in the function $I_{S C \text { norm }}$

Figure 5 presents a distribution of points $\left(U_{O C \text { norm }}, I_{S C \text { norm }}\right)$ for parametrically changing temperature $T_{C}$ of a PV module, further referred to as the graph of the normalised voltage of an open circuit $U_{O C \text { norm }}$ of the module in the function of its normalised short-circuit current $I_{S C}$ norm. The use of normalisation allows to considerably extend the graph's functionality. This allows to directly compare different modules with different powers and output voltages (see Fig. 6). Taking into consideration that in reality there is very little influence of temperature $^{5}$ in modules/cells on the value of $I_{S C}$, current; normalisation of $I_{S C}$ current to the values achieved in STC conditions, allows to rescale the axis and read the cell/module voltage drop in the function of the solar radiation value $\left(I_{S C} / I_{S C} S T C=1\right.$ for $\left.G_{P O A}=1000 \mathrm{~W} / \mathrm{m}^{2}\right)$. More details on the temperature interrelations, temperature adjustment of I-V characteristics and the use of PV cells/modules as lighting level sensors and their operational temperature, can be found in [26-38].

Plotting the cut-off/boundary straight-line on the level of $0.7 \cdot U_{\text {OC norm }}$ (i.e. a $3 \mathrm{~dB}$ straight-line of voltage drop $U_{O C}$ ), we obtain the possibility to determine the minimum value of solar radiation, for which the value of the voltage of an open circuit of the $U_{O C}$ module does not drop below 70\% of the value in STC conditions, yet. Moreover, taking into consideration that in the typical, commercial PV modules: $\underline{U}_{m} \cong(0.80-0.85) \cdot U_{O C}[39,40]$, we gain the possibility to estimate the minimum value of solar radiation required for the

\footnotetext{
${ }^{5}$ Cells/modules have very low temperature coefficients for $I_{S C}$ current.
} 
operation of the $P V$ inverter with the modules with $U_{m}$ voltage, for the designed connections configuration $^{6}$. Application of the log-lin scale in the graph provides the possibility of performing detailed analyses of the PV conversion in the range of low and very low values of solar radiation (the property of a logarithmic scale). It is useful in the analyses of modules operation during cloudy days, with low and very low values of solar radiation, defined in the IEC 61853 (DRAFT 82/254) [41] standard as LILT (Low Irradiance, Low Temperature - a typical winter day with low value of solar radiation intensity), LIMT (Low Irradiance, Medium Temperature - a warm and very cloudy day) and MIMT (Medium Irradiance, Medium Temperature - a typical warm but cloudy day). During those days, an average temperature of operating PV modules is not much higher that the ambient temperature, which is determined in line with (23) [42]:

$$
T_{C}=T_{a m b}+G_{0} \frac{N O C T-20}{800}\left[{ }^{\circ} \mathrm{C}\right]
$$

where: $G_{0}\left[\mathrm{~W} / \mathrm{m}^{2}\right]$ - the global value of solar radiation on the Earth's surface, NOCT - Nominal Operating Cell Temperature) ${ }^{7}$.

Taking into consideration typical atmospheric conditions in the regions of higher geographical latitudes - pursuant to (23), the most frequent temperatures $\left(T_{C}\right)$ of operating PV modules, for typical days of the area, have been determined. The calculations assumed an average value of NOCT coefficient of modules equal $42^{\circ} \mathrm{C}$. A set of modules temperatures $T_{C}=\{-3 ; 6 ; 15 ; 25 ; 40 ; 50 ; 60\}$ in $\left[{ }^{\circ} \mathrm{C}\right]$ obtained in this way, in which four first elements reflect the conditions of low or very low radiation values for cool/moderately warm days and others - to typical day conditions in the summer season. Next, these values were used as temperature parameters $T_{C}$ for compiling the graphs $U_{O C \text { norm }}=f\left(I_{S C \text { norm }}\right)$ in Figure 5. Points of intersection of each graph with the set-off/border straight line on the level of $0.7 \cdot U_{O C \text { norm }}$, marked with a grey ellipse outline the area of $\underline{\boldsymbol{P} \boldsymbol{V} \text { conversion }}$ sensitivity. In the case of the module from Figure 5, this area is from the section $25.8 ; 37.5 \mathrm{~W} / \mathrm{m}^{2}$ for the module temperature $T_{C}$ from the range $-3-25^{\circ} \mathrm{C}$. It can be seen that for higher temperatures $T_{C}$, there is no intersection of characteristics with the set-off/border straight line. This is caused by the fact that the temperature $T_{C}$ above $40^{\circ} \mathrm{C}$ can be achieved by the module illuminated by the direct component in the range of higher values of solar radiation, for which the module voltage is much higher than $0.7 \cdot U_{O C}$ norm. Whereas all transient states, e.g. caused by momentary shading, a cloud, of the module heated by the sun, are levelled by averaging (previously reported characteristics of the above mentioned graph).

Such a prepared graph $U_{O C \text { norm }}=\mathrm{f}\left(I_{S C \text { norm }}\right)$ from Figure 5 presents a peculiar characteristics of a PV module operation in the conditions of an open space (outdoor), dedicated for the final location of its operation and, due to its functionality, it can become a very useful engineering tool for optimal design of $P V$ systems.

\footnotetext{
${ }^{6}$ Example. Let us analyse a mc-Si module with the parameters: $P_{m}=24 \mathrm{~W}_{\mathrm{p}}, U_{O C}=21 \mathrm{~V}, U_{m}=17.7 \mathrm{~V}$. The $30 \%$ threshold of $U_{O C}$ drop: is determined by $G_{P O A \text { min }}$ for which: $U_{O C}=14.7 \mathrm{~V}, U_{m}=11.76 \mathrm{~V}$, i.e. further drop below the threshold causes the lack of technical capacity for direct charging of an acid battery by the PV module. In the case of a PV inverter, it causes drop of voltage below the minimum limit of catching/capturing of the MPP tracking system of the converter, which cannot be lower than: $n \cdot U_{m}$, where $n$ - quantity(number) of modules in a string branch.

${ }^{7}$ This is the temperature achieved by the module at the radiation intensity of $G_{0}=800 \mathrm{~W} / \mathrm{m}^{2}$, ambient temperature $T_{a m b}=20^{\circ} \mathrm{C}$ and wind speed of $1 \mathrm{~m} / \mathrm{s}$.
} 
Figure 6 presents the use of the standardised voltage value graph $U_{O C}$ norm in the function of its standardised current value $I_{S C \text { norm }}$ in order to compare their operation efficiency in the conditions of low solar radiation values. Two different modules with different powers, voltages and output currents were compared. The first, made of crystalline silicon (c-Si) with power $P_{m}=27 \mathrm{~W}_{\mathrm{p}}$, voltage $U_{O C}=20 \mathrm{~V}$ and current $I_{S C}=1.97 \mathrm{~A}$, and the second, made of amorphous silicon (a-Si_SJ) with power $P_{m}=11.15 \mathrm{~W}_{\mathrm{p}}$, voltage $U_{O C}=21.8 \mathrm{~V}$ and current $I_{S C}=1.05 \mathrm{~A}$. What can be instantly observed is that the application of the presented method (see Fig. 6) for comparing efficiencies of these extremely different modules, does not cause any complications. One can read directly from the graph the so called $P V$ conversion sensitivity area for each module separately, which amounts to: for the crystalline module (c-Si) $25.5-37.5 \mathrm{~W} / \mathrm{m}^{2}$ whereas for the amorphous silicon module (a-SI_SJ) 4.5-9.5 W/m². This signifies that in early morning and late evening hours, when the PV system powered with crystalline modules had already stopped operation, the PV system powered with amorphous silicon modules will still obtain voltage from the modules on the nominal level (i.e. maintaining a $3 \mathrm{~dB}$ drop). A similar situation will take place on cloudy days or with very low solar radiation intensity values. The above mentioned estimates have been confirmed by experiments in real conditions of their operation, which is presented in Figure 7 and in [43].

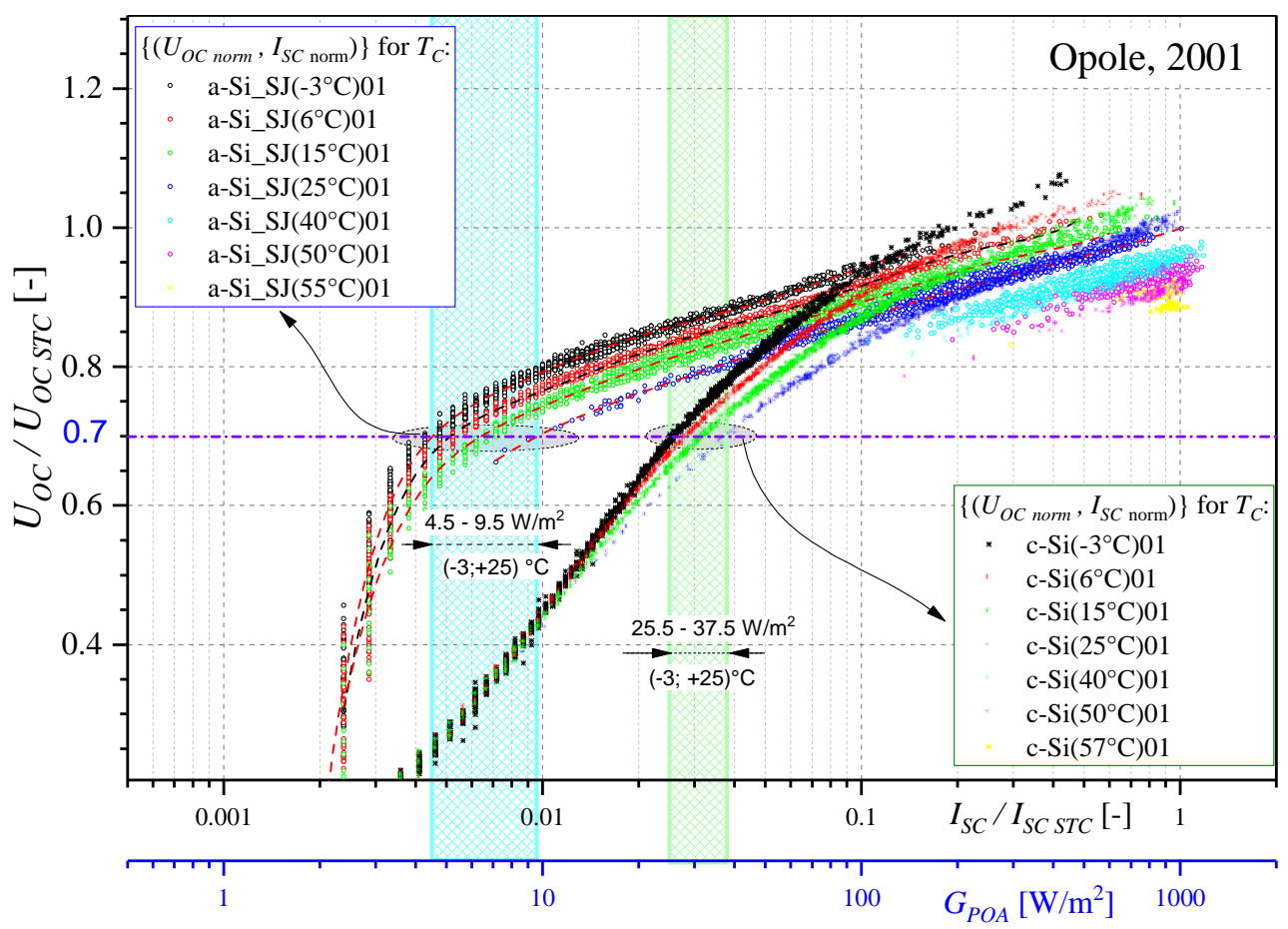

Fig. 6. A comparison of operation characteristics of two diametrically different modules: a $12 \mathrm{~W}_{\mathrm{p}}$ module with a-SI_SJ with a $30 \mathrm{~W}_{\mathrm{p}}$ module with c-Si 

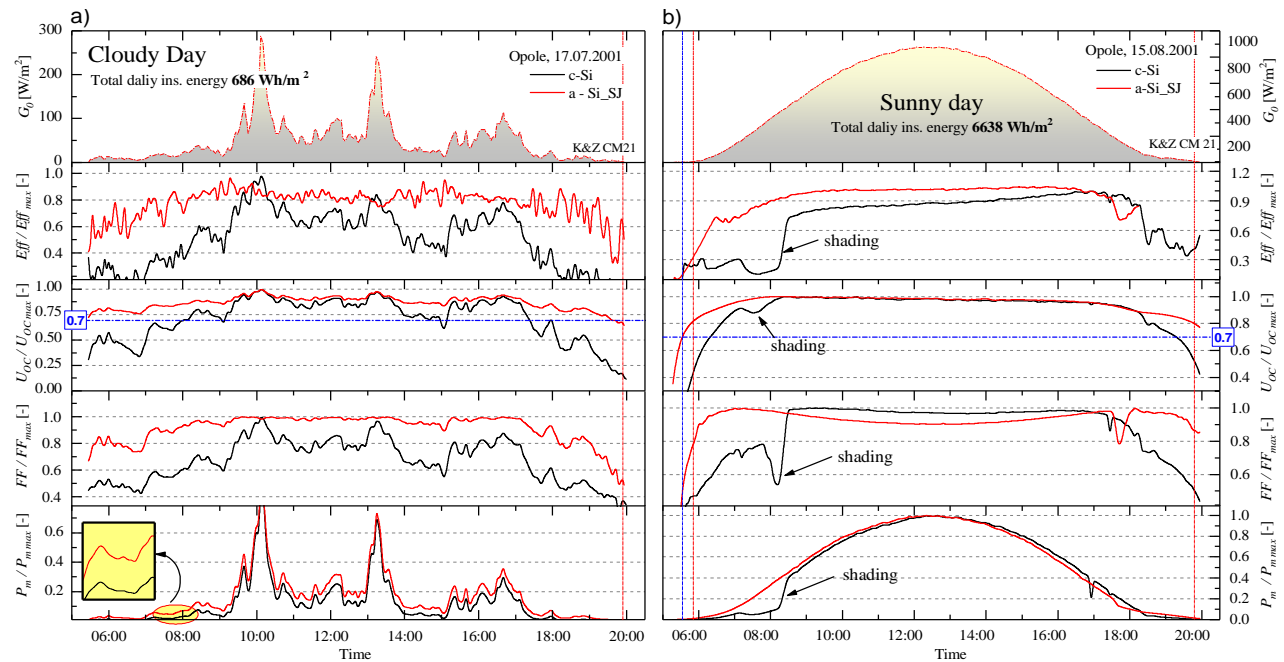

Fig. 7. Comparison of PV conversion efficiency of two modules with operation characteristics from Fig. 6 for two extremely different days: a) cloudy and warm, i.e. LIMT type, and b) sunny and hot, i.e. HIHT type

From the analysis of the PV modules suitability to operate in the conditions of low solar radiation, i.e. during cloudy days (Fig. 7a), it can be concluded that the amorphous silicon module, during all cloudy day, maintains its $U_{O C}$ voltage within the nominal value range, i.e. not exceeding a $3 \mathrm{~dB}$ drop of the nominal voltage value. A very low $P V$ conversion sensitivity area $4.5-9.5 \mathrm{~W} / \mathrm{m}^{2}$ of the a-Si_SJ module caused that during the measurement registration, i.e. from dawn to dusk, it is very difficult to catch the moment of the $3 \mathrm{~dB}$ drop of $U_{O C}$ voltage - the automatics of the measuring system identified the moment of sunset much earlier, and switched off the measuring system, as if it was already night. Other parameters, such as $F F, E f f$ were found to stay all day above 0.7 and 0.6 of their maximum values, respectively. The analysis of operation during a sunny day shows a $3 \mathrm{~dB}$ drop of voltage for the a-Si_SJ module, however, the drop occurred only after sunset (Fig. 7b). That means that even the operation with very dispersed radiation of very little value after sunset is sufficient in certain time period, for the correct operation of the module (i.e. maintaining the nominal voltage). Of course the power generated then is considerably lower, because the quantity of energy per module is also much lower.

\section{Research results}

The research station for testing photovoltaic modules (Fig. 8) was initiated in University of Opole in September 1998, initially with two $30 \mathrm{~W}_{\mathrm{p}}$ modules made of monocrystalline silicon (c-Si) [25], marked as modules 7 and 8 (e.g. M8_c-Si). The process of calibration and start-up were carried out until 2001. Other modules were added in the following periods:

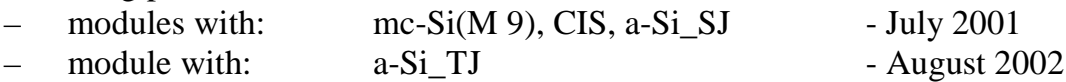

The first measuring channel with the installed M7_c-Si module was used until 2006 to carry out the analysis of the gain from using the follow-up system. The measuring channel 
was used to carry out comparative analyses for testing the selected PV modules, Currently, since 2012 comparative research has been carried out with the polycrystalline silicon M7_mc-Si module.

Initially, for each PV module individually, after connecting to the measuring system, their parameters were measured during operation in outdoor conditions. The obtained measurement results, after referring to STC conditions with the use of Blaesser procedures [30] were used later as the point of reference for individual PV modules (Table 1).

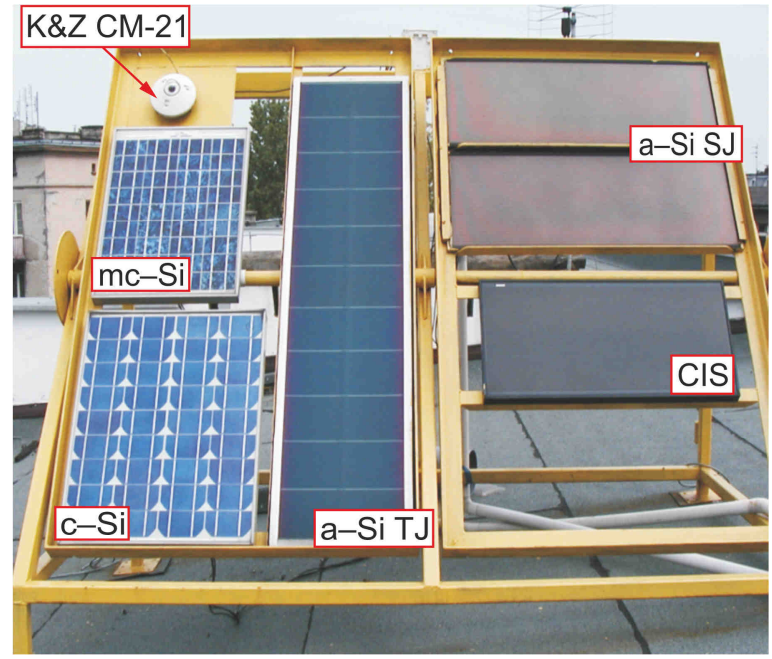

Fig. 8. Research station to test PV modules in the outdoor conditions [25]

Summary of technical parameters of the tested modules with reference of STC conditions

\begin{tabular}{|c|c|c|c|c|c|c|}
\hline \multirow{2}{*}{$\begin{array}{c}\text { PV module } \\
\text { (No._absorber) }\end{array}$} & \multirow{2}{*}{$\boldsymbol{S}_{\boldsymbol{P V}}$} & \multicolumn{5}{|c|}{ PV modules parameters in STC conditions } \\
\cline { 2 - 6 } & {$\left[\mathbf{m}^{\mathbf{2}}\right]$} & $\boldsymbol{P}_{\boldsymbol{m}}$ & $\boldsymbol{I}_{\boldsymbol{S C}}$ & $\boldsymbol{U}_{\boldsymbol{O C}}$ & $\boldsymbol{I}_{\boldsymbol{m}}$ & $\boldsymbol{E}_{f f}$ \\
\hline M7_mc-Si & 0.229 & {$\left[\mathbf{W}_{\mathbf{p}}\right]$} & {$[\mathbf{A}]$} & {$[\mathbf{V}]$} & {$[\mathbf{A}]$} & {$[\%]$} \\
\hline M8_c-Si & 0.309 & 24 & 1.49 & 21 & 1.35 & 10.5 \\
\hline M9_mc-Si & 0.228 & 20.4 & 1.47 & 20 & 1.79 & 8.72 \\
\hline M10_CIS & 0.231 & 23.9 & 1.68 & 20.7 & 1.29 & 9.02 \\
\hline M11_a-Si_SJ & 0.263 & 11.15 & 1.05 & 21.8 & 1.45 & 10.35 \\
\hline M12_a-Si_TJ & 0.522 & 32 & 2.36 & 22.5 & 1.94 & 4.19 \\
\hline
\end{tabular}

July 2001 was set as the start of the testing period of modules, except the module with a-Si_TJ, where the start was set in August 2002. The tests have been continuing until today. The tested PV modules were installed in the platform inclined at the $38^{\circ}$ angle on the roof of a University building at Kominka St. The modules operate in extremely adverse thermal conditions, especially during hot summer months. Very intense solar radiation together with very high ambient temperatures, plus intense infra-red radiation from the roof cover (black asphalt roofing paper) caused fast ageing of the tested modules (degradation of their structure). There were several breaks in their operation due to repair works on the roof of the building or temporary failures of the measuring system. 


\section{A study of PV modules operation characteristics in the conditions of low solar radiation intensity}

Taking into consideration the above mentioned breaks in operation of the measuring system, only the selected data, most complete results from continuous measurements, have been used in the study. The data from the initial period of exploitation were used for the presentation of the characteristics of operation of thin-layer modules made of amorphous silicon (i.e. of a-Si_SJ and a-SI_TJ) (Fig. 9d, e) and CIS (Fig. 9c), due to the occurring phenomenon of absorber degradation. It was not necessary in the case of other modules and the current data from 2016 were used. Table 2 presents PV conversion limit sensitivity values taken from Figure 9, for the four $T_{C}$ temperatures, which most frequently occur during cool-warm days with low and very low solar radiation values. That is during cloudy days, described by the standard [41] as MILT, MIMT, LILT, LIMT.
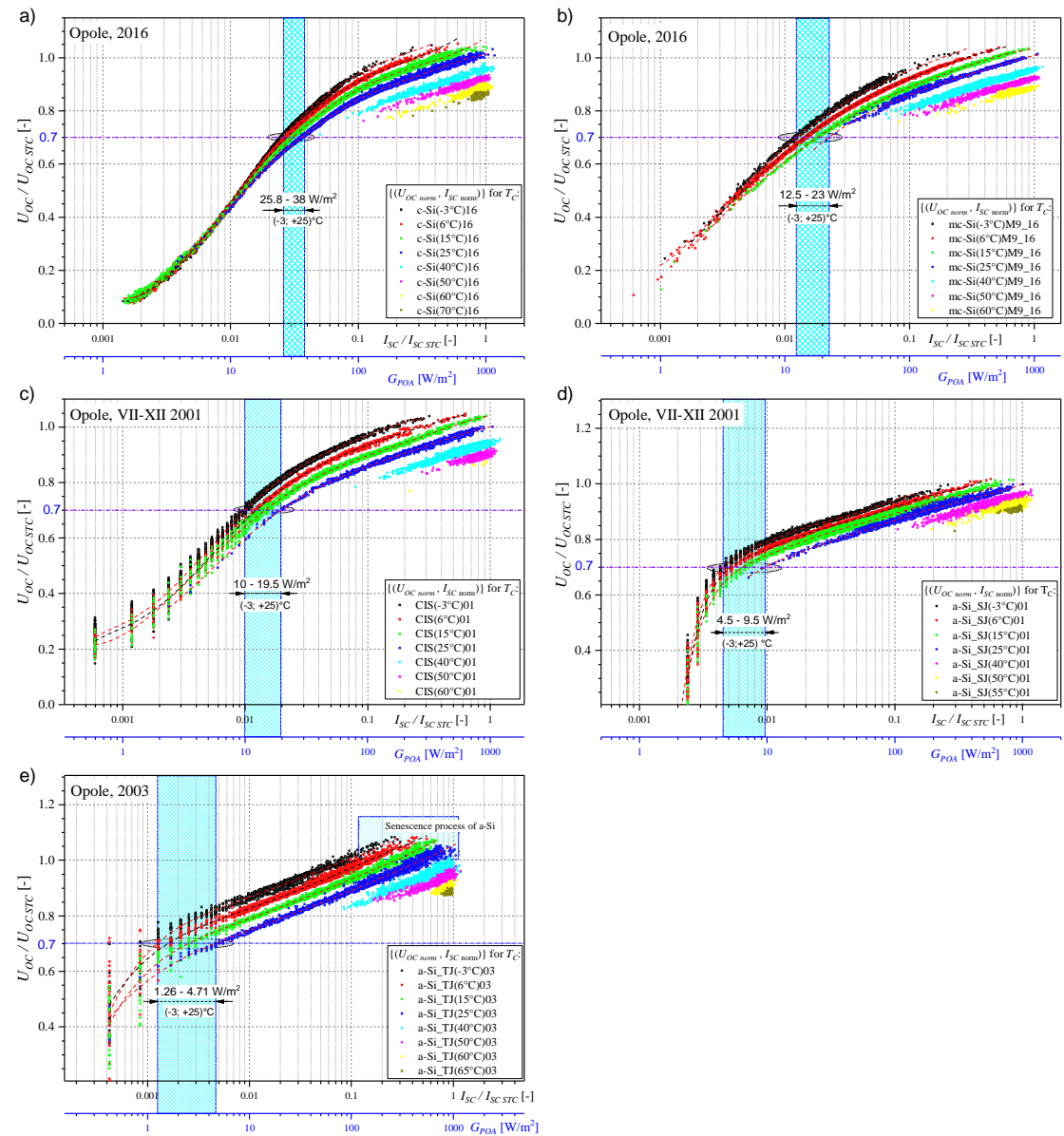

Fig. 9. The graph of voltage $U_{O C}$ norm in the function of current $I_{S C}$ norm for parametrically variable temperature of the module $T_{C}$ - i.e. characteristics of PV modules operations: a) crystalline silicon c-Si; b) polycrystalline silicon mc-S; c) CIS; d) amorphous single-joint a-SI_SJ; e) amorphous triple-joint a-SI_TJ 
PV conversion limit sensitivity values of a module for various temperatures $T_{C}$ - taken from Fig. 9)

\begin{tabular}{|c|c|c|c|c|}
\hline \multirow{3}{*}{$\begin{array}{c}\text { PV module } \\
\text { absorber (No.) }\end{array}$} & \multicolumn{4}{|c|}{ PV conversion limit sensitivity for the temperature $T_{C}\left[{ }^{\circ} \mathrm{C}\right]$} \\
\hline & $\mathbf{S}\left(-3^{\circ} \mathbf{C}\right)$ & $\mathrm{S}\left(6^{\circ} \mathrm{C}\right)$ & $\mathbf{S}\left(15^{\circ} \mathrm{C}\right)$ & $\mathrm{S}\left(25^{\circ} \mathrm{C}\right)$ \\
\hline & {$\left[\mathbf{W} / \mathbf{m}^{2}\right]$} & {$\left[\mathbf{W} / \mathbf{m}^{2}\right]$} & {$\left[\mathbf{W} / \mathbf{m}^{2}\right]$} & {$\left[\mathrm{W} / \mathbf{m}^{2}\right]$} \\
\hline c-Si (M8) & 25.8 & 27.4 & 30.9 & 38.0 \\
\hline mc-Si (M9) & 12.5 & 14.6 & 18.0 & 23.0 \\
\hline CIS (M10) & 10 & 12.2 & 14.5 & 19.5 \\
\hline a-Si_SJ (M11) & 4.5 & 5.1 & 6.3 & 9.5 \\
\hline a-Si_TJ (M12) & 1.26 & 1.62 & 2.5 & 4.71 \\
\hline
\end{tabular}

a)

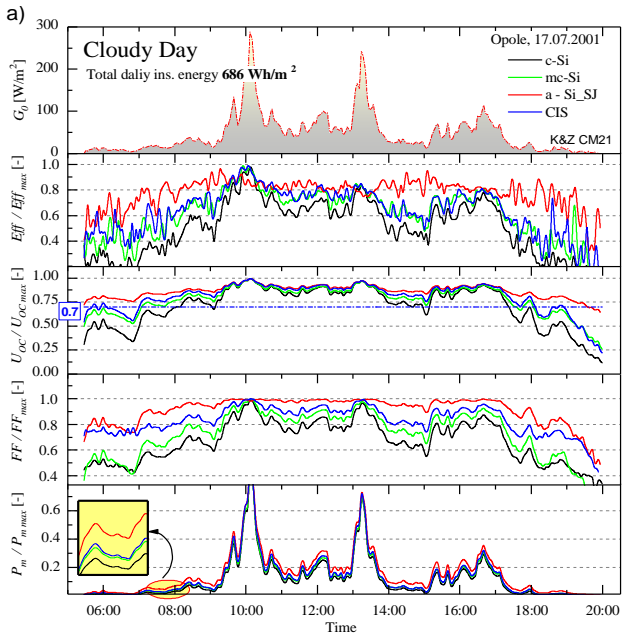

b)

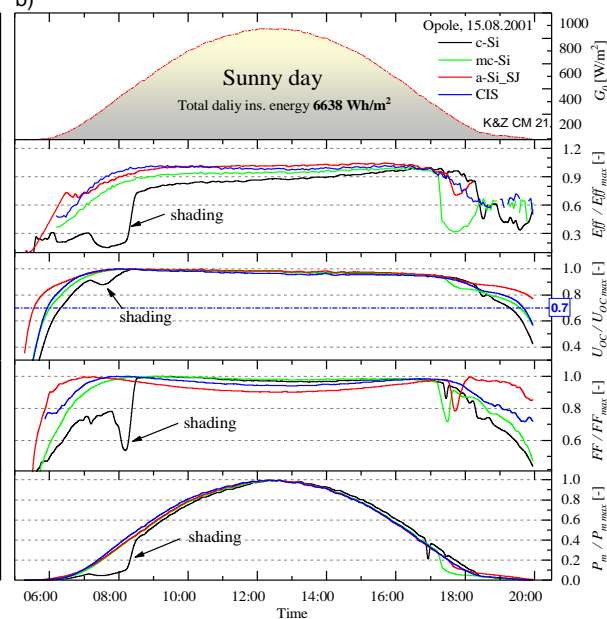

Fig. 10. Comparison of conversion efficiency of PV modules with operation characteristics from Figure 7 for extremely different days: a) cloudy and warm, i.e. LIMT type, and b) sunny and hot, i.e. HIHT type. The characteristics of amorphous triple-joint module (a-Si_TJ) is not in the figure, because such a module was not installed yet in 2001
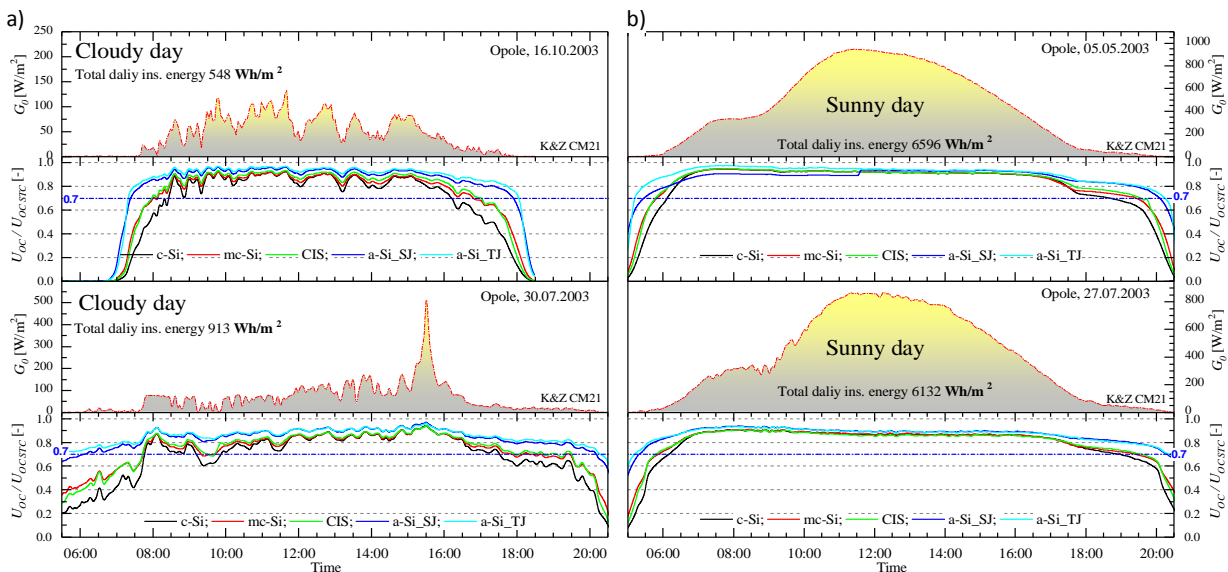

Fig. 11. Comparison of conversion efficiency of PV modules with operation characteristics from Figure 7 for two extremely different days: a) cloudy and warm, i.e. LIMT type, and b) sunny and hot, i.e. HIHT type 
The presented in Figure 9 characteristics of different PV modules operation, together with Table 2 containing PV conversion limit sensitivity for various modules - may be very useful in estimating their usefulness to operate in various potential locations. Such locations offer specific solar light levels and structures, i.e. the share/content of the dispersed and direct elements in total solar radiation reaching the surface of the planned installation panel of PV modules. This refers not only to an open, illuminated area but also operation of modules in shaded places, such as buildings façades on other than southern sides, including walls of buildings, stained glass panels in windows, which do not receive the direct solar radiation for various reasons, e.g. shadows of other buildings, area surface type, etc. An analysis of the above mentioned data proves that an ideal solution for installations in shady areas in extremely unfavourable conditions (i.e. with very low solar radiation) is to install amorphous silicon single-joint or multi-joint modules. Verification of this estimate has been confirmed by experiments in real conditions of their operation, which is presented in Figures 10 and 11.

\section{Application of a two-day model in assessment of PV modules degradation scale}
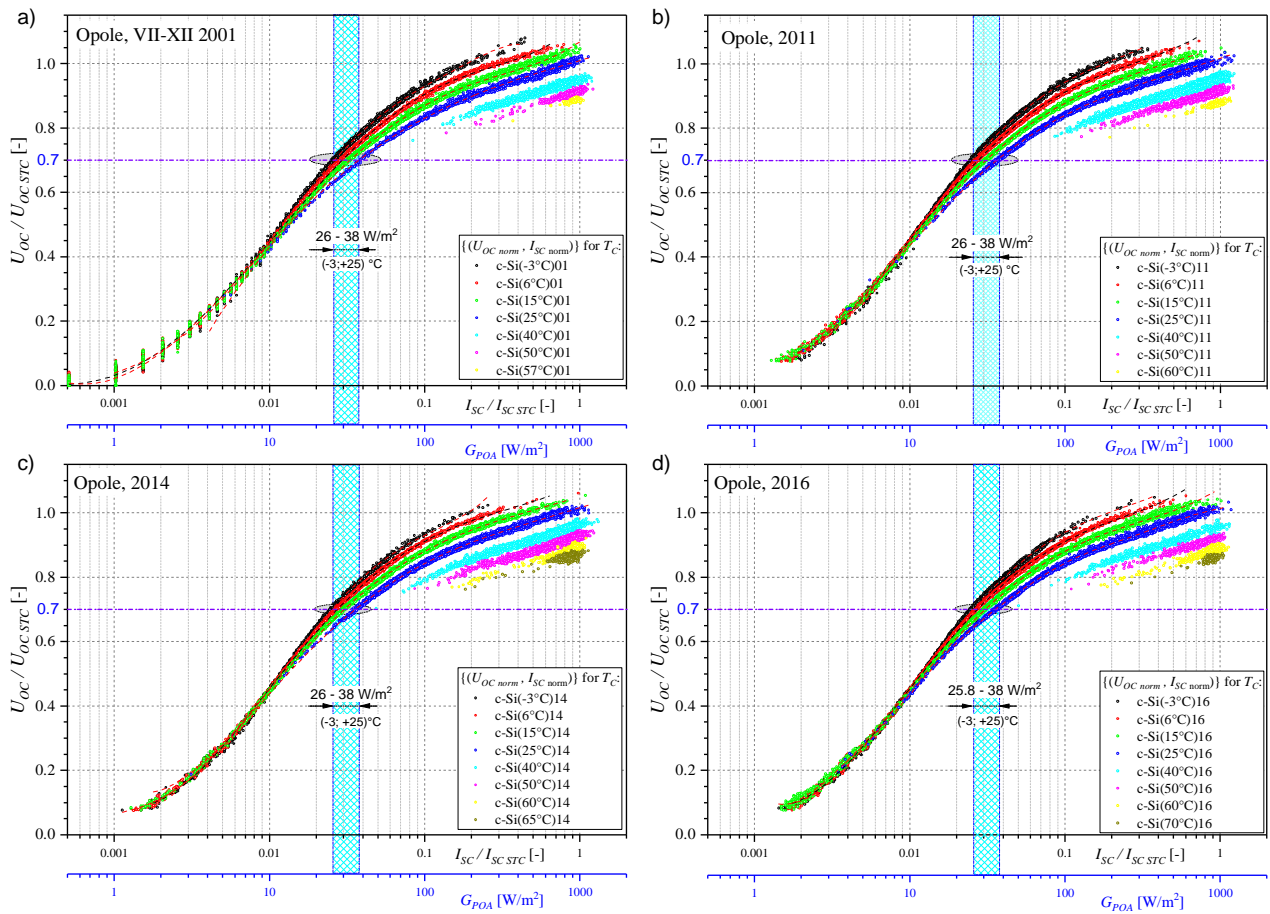

Fig. 12. Changes in the graph of voltage $U_{O C}$ norm in the function of current $I_{S C}$ norm for parametrically variable temperature of the module $T_{C}$ - i.e. characteristics of a crystalline silicone $c$-Si module operation during 15 years of its exploitation period 

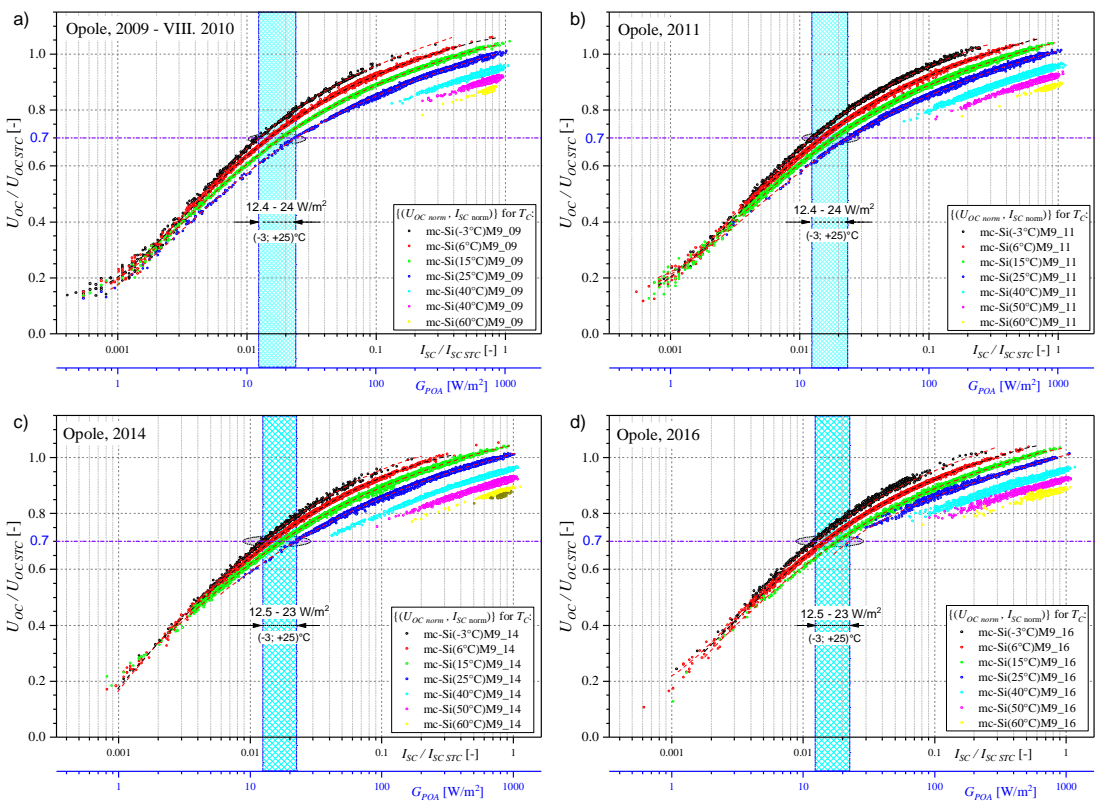

Fig. 13. Changes in the graph of voltage $U_{O C \text { norm }}$ in the function of current $I_{S C}$ norm for parametrically variable temperature of the module $T_{C}$ - i.e. characteristics of a polycrystalline silicon $m c-S i$ module operation during 8 years of its exploitation period
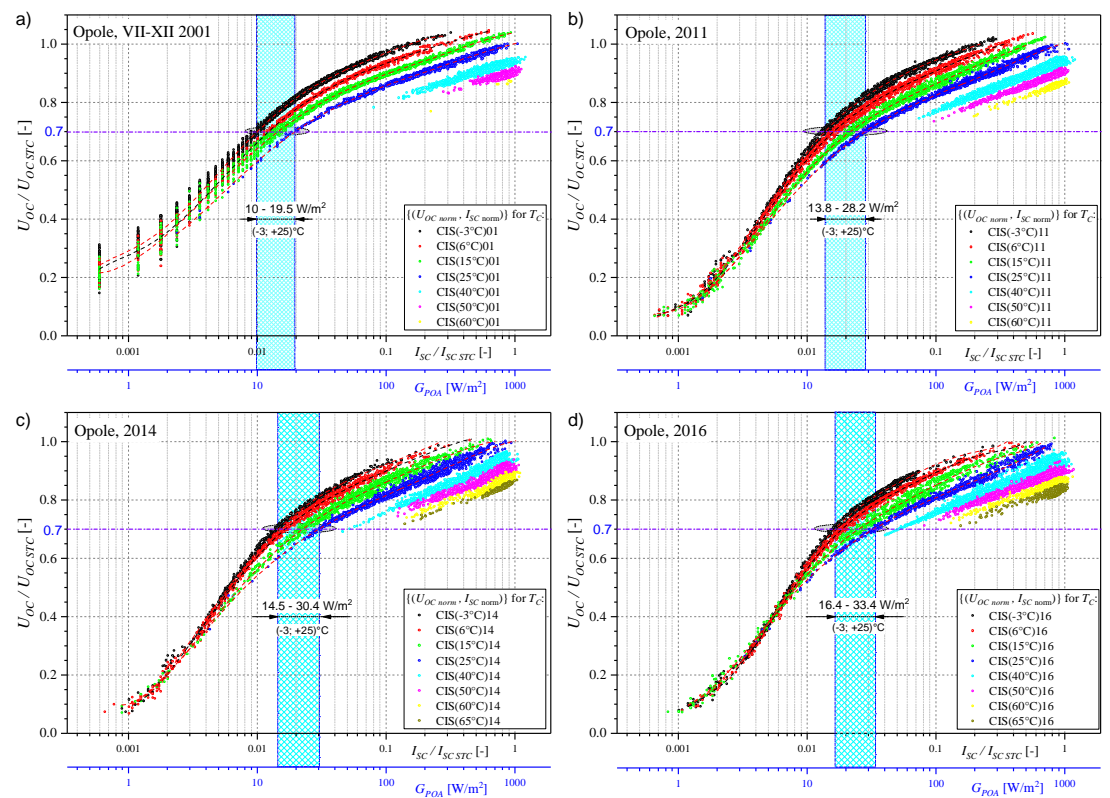

Fig. 14. Changes in the graph of voltage $U_{O C}$ norm in the function of current $I_{S C}$ norm for parametrically variable temperature of the module $T_{C}$ - i.e. characteristics of a $\underline{C I S}$ module operation during 15 years of its exploitation period 

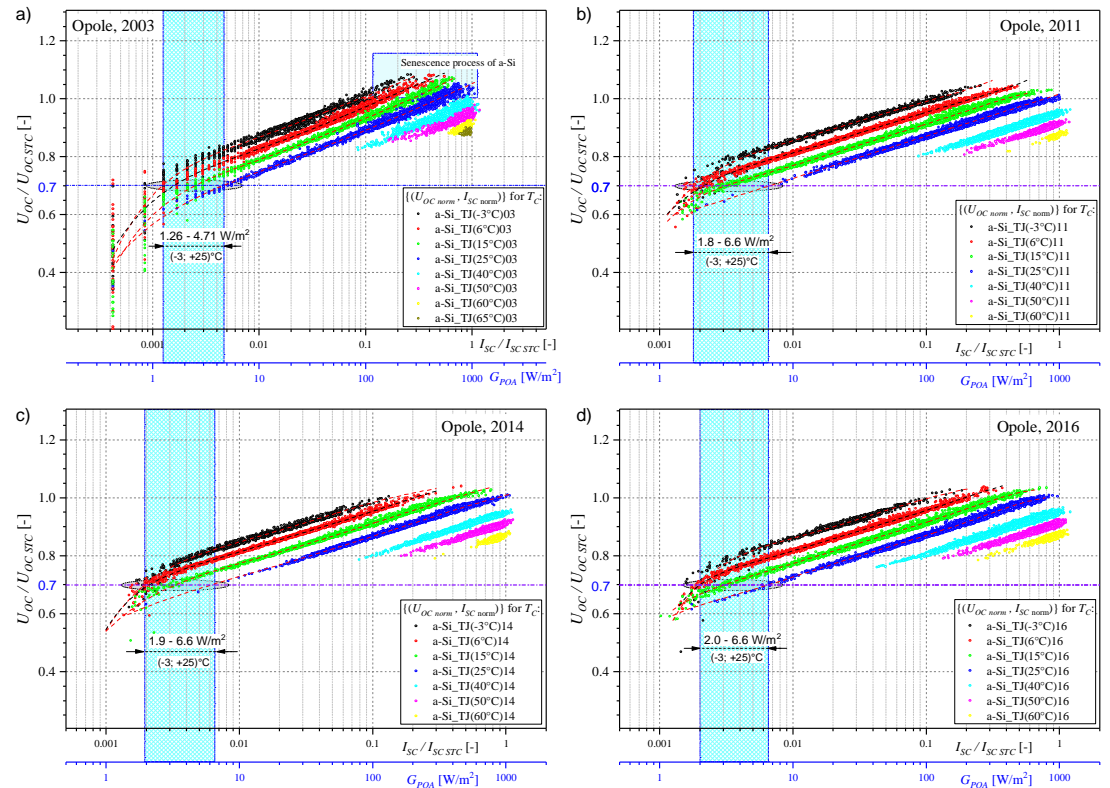

Fig. 15. Changes in the graph of voltage $U_{O C}$ norm in the function of current $I_{S C}$ norm for parametrically variable temperature of the module $T_{C}$ - i.e. characteristics of an amorphous silicon triple-joint $\underline{a-S i} T J$ module operation during 14 years of its exploitation period

As noticed above, the method of function analysis with the use of the log-lin scale, with reference to the $U_{O C \text { norm }}=f\left(I_{S C \text { norm }}\right)$ graphs, has specific characteristics in the range of low and very low values of solar radiation falling on the modules surface. This method does not have such characteristics and is not useful in the range of high values. Therefore, the application of the method in analysis of the change of conversion sensitivity of various PV modules, as the effect of their material-construction degradation, will be presented.

Figures 12-16 presents the changes in the pairs of points distribution ( $\left.U_{O C \text { norm, }} I_{S C \text { norm }}\right)$ for parametrically different variable value of temperature $T_{C}$ of modules during several years in extremely difficult conditions of their exploitation. However, for the crystalline silicon module c-Si module (Fig. 12) and polycrystalline mc-Si module (Fig. 13), during the period of, respectively: 15 and 18 years of operation, no drop in PV conversion sensitivity was detected, which is, respectively: $26-38 \mathrm{~W} / \mathrm{m}^{2}$ and $12.4-23 \mathrm{~W} / \mathrm{m}^{2}$ for the temperatures within the range $-3-25^{\circ} \mathrm{C}$. That means that these modules show no signs of material degradation in their absorber after several years of exploitation.

The situation of thin-layer modules is quite different. The analysis of Figure 14 of the CIS module shows a very distinct drop of PV conversion sensitivity, from the value $10-19.5 \mathrm{~W} / \mathrm{m}^{2}$ in 2001 , through $13-28.2 \mathrm{~W} / \mathrm{m}^{2}$ in $2011,14.5-30.4 \mathrm{~W} / \mathrm{m}^{2}$ in 2014 to $16.4-33.4 \mathrm{~W} / \mathrm{m}^{2}$ in 2016 , for the same temperature range, i.e. $-3-25^{\circ} \mathrm{C}$. In consequence, the module's year energy efficiency, calculated according to (24), decreased by approximately $2.25 \%$, i.e. there was decrease of its original value from $9.6 \%$ to approximately $7.0 \%$ (Fig. 17) [44]. 


$$
\eta_{E_{\text {year }}}=\frac{\int_{0}^{\text {year }} P_{m}(t) d t}{A \int_{0}^{\text {year }} G_{0}(t) d t}
$$
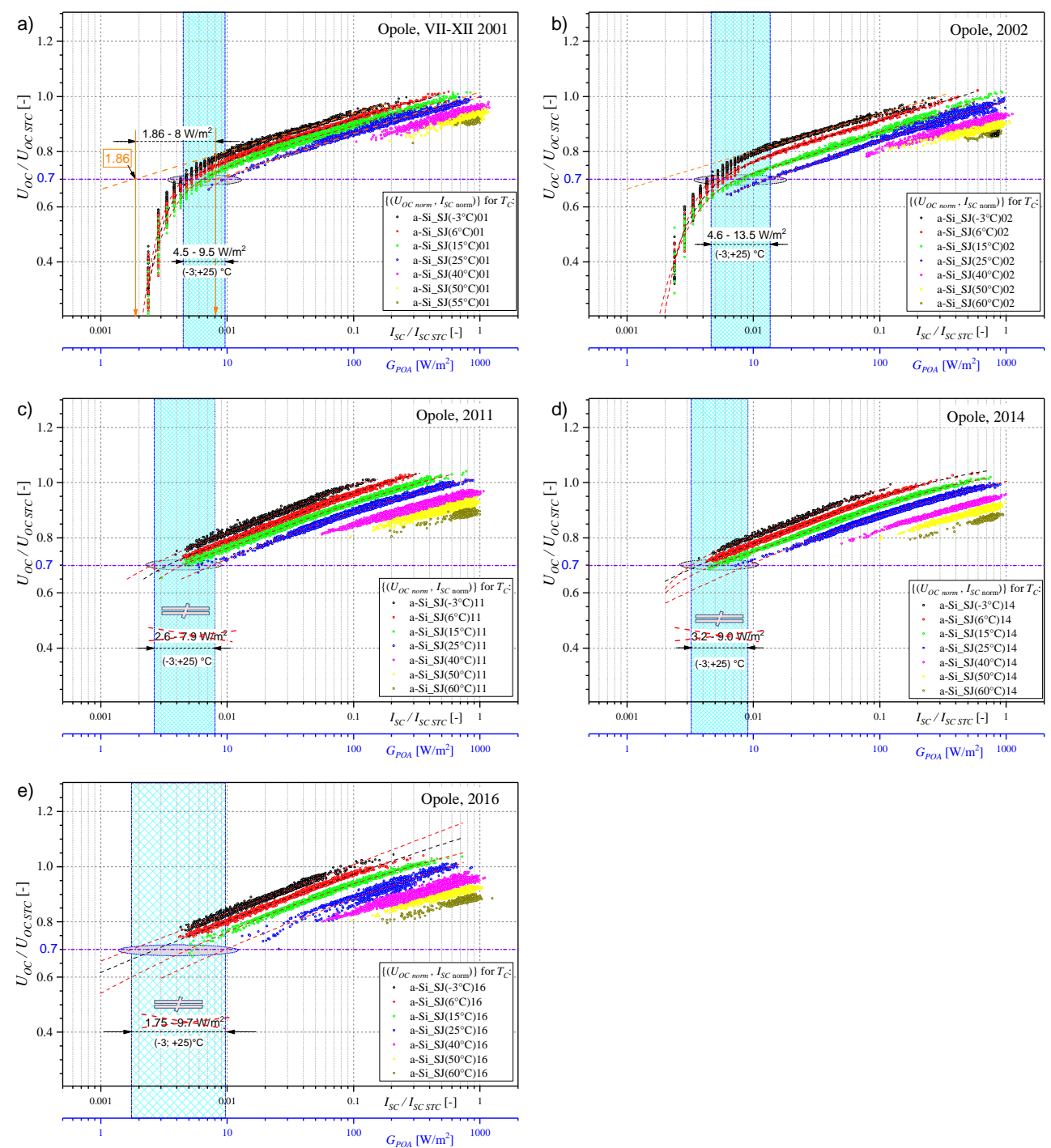

Fig. 16. Changes in the graph of voltage $U_{O C}$ norm in the function of current $I_{S C}$ norm for parametrically variable temperature of the module $T_{C}$ - i.e. characteristics of an amorphous silicon single-joint a-Si_SJ module operation during 15 years of its exploitation period 


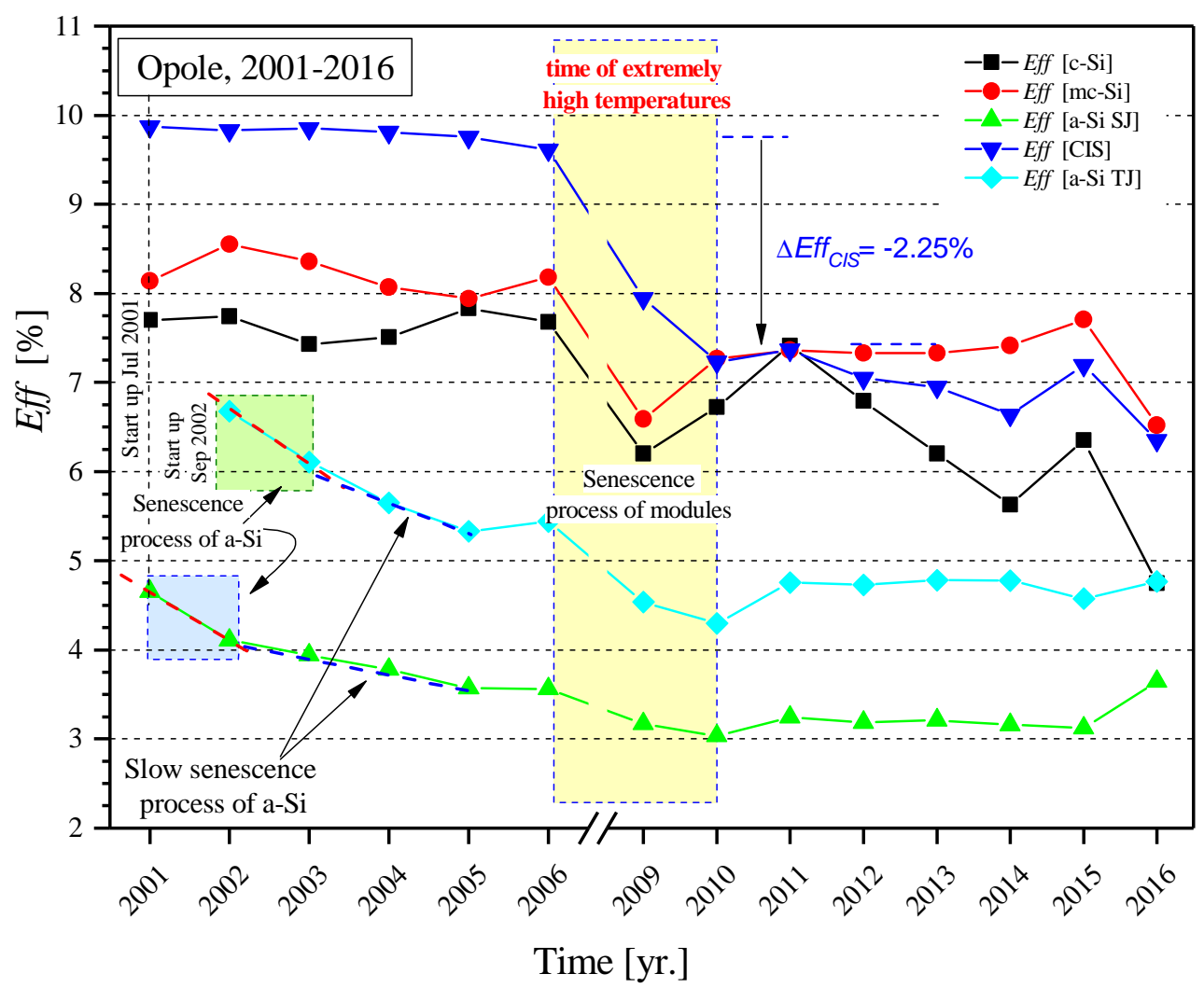

Fig. 17. Ageing processes in the PV modules tested during the years 2001-2016 - the level of year energy efficiency of the modules determined according to Eq. (24)

In the case of an amorphous silicon triple-joint module (Fig. 15), the ageing changes in effect of absorber degradation were the least visible, out of the three models. There was a little decrease of PV conversion sensitivity range for the discussed temperatures, i.e. from $1.26-4.71 \mathrm{~W} / \mathrm{m}^{2}$ in 2003 , through $1.8-6.6 \mathrm{~W} / \mathrm{m}^{2}$ in $2011,1.9-6.6 \mathrm{~W} / \mathrm{m}^{2}$ in 2014 to $2.0-6.6 \mathrm{~W} / \mathrm{m}^{2}$ in 2016 , which resulted in decrease of its original year energy efficiency from 6 to approximately $4.8 \%$. Whereas, in the case of an amorphous silicon single-joint module, there was a rapid deterioration of PV conversion sensitivity range, from $4.5-9.5 \mathrm{~W} / \mathrm{m}^{2}$ in 2001 , when in 2002 it already was $(4.6-13.5) \mathrm{W} / \mathrm{m}^{2}$ for the same operating temperature of the modules. It has been quite impossible to read PV conversion sensitivity at $3 \mathrm{~dB}$ drop of $U_{O C}$ voltage, since 2009 . The lack of parts of characteristics in the area of $I_{02}$ component domination of dark current (recombination component of the space charge region). The inclination of the characteristics from the area of $I_{01}$ component domination (recombination component of quasi-neutral areas) has been the same for 15 years - the same PV conversion ability in the range of medium and high values of solar radiation. However, the area marked by the lines of their approximation with the threshold $0.7 \cdot U_{O C}$ do not mark the $\mathrm{PV}$ conversion range on the $3 \mathrm{~dB}$ level drop of $U_{O C}$ voltage, because no such pairs of points occur in reality. In effect, the module operates as before, in the conditions of medium and 
high values of radiation intensity, only with the reduced original year energy efficiency from 4.19 to $3.2 \%$. The module, however, does not have the valuable feature it possessed before - the possibility of PV conversion at the illumination level close do darkness, even in the conditions of "moonlight."

This phenomenon is often unnoticed during exploitation and a user is convinced that the module operates with the same conversion sensitivity. Figure 18 presents a computer screen of the PV modules testing system, installed in University of Opole. The figure on the left presents the operating condition of the tested PV modules after a hot summer, on a sunny, autumn day. For the solar radiation intensity $\left(G_{P O A}\right)$ falling on modules surface above $700 \mathrm{~W} / \mathrm{m}^{2}$ - all $I-U$ characteristics are the same - almost ideally, and the readings of the registered values of energy and charge accumulation by the tested modules raised no concerns. Only in the case of radiation drop value below $240 \mathrm{~W} / \mathrm{m}^{2}$ (see Figure $18 \mathrm{~b}$, one can observe in $I-U$ characteristics of the M11- a-Si_SJ module - discontinuity of $\underline{\text { the open circuit } U_{O C} \text { voltage. }}$

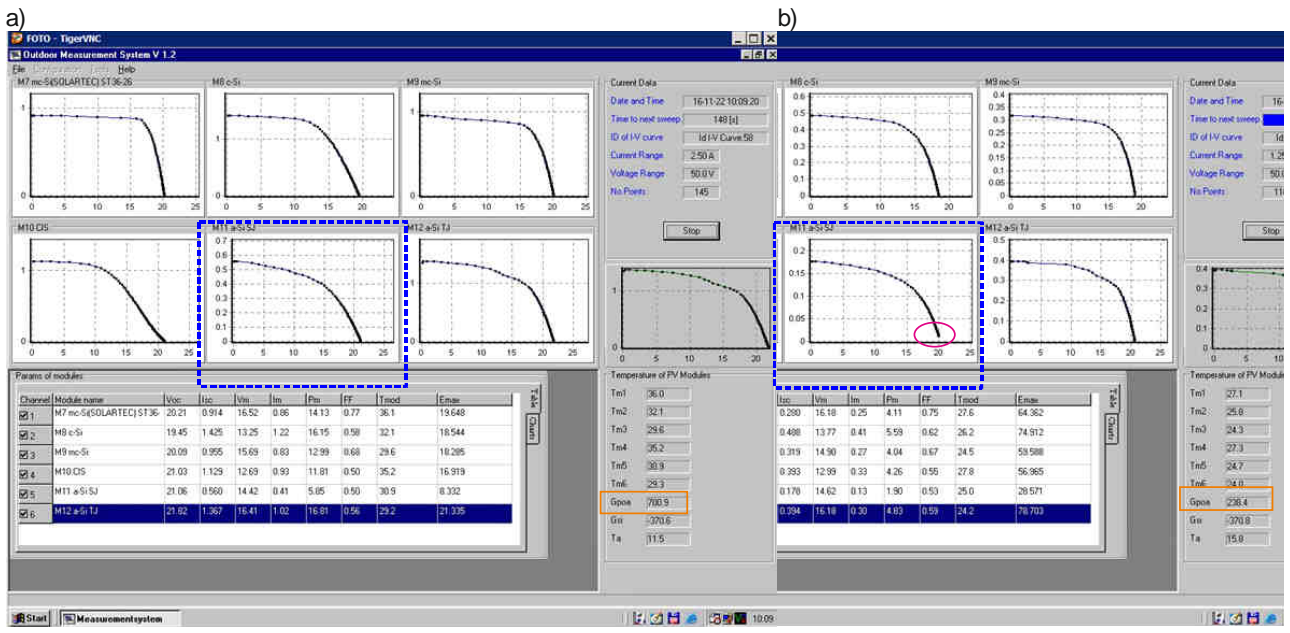

Fig. 18. The monitor screens of the PV modules testing system installed in University of Opole after 15 years of exploitation, during testing after a hot summer on an autumn day: a) warm and sunny, i.e. 22.11 .2016 at 10:09 am $\left(G_{P O A}=700.9 \mathrm{~W} / \mathrm{m}^{2}, T_{a m b}=11.5^{\circ} \mathrm{C}, T_{C}=30.9^{\circ} \mathrm{C}\right)$; b) warm and cloudy, i.e. 21.11 .2016 at $2: 46 \mathrm{pm}\left(G_{P O A}=238.4 \mathrm{~W} / \mathrm{m}^{2}, T_{a m b}=15.8^{\circ} \mathrm{C}, T_{C}=24.7^{\circ} \mathrm{C}\right)$. The occurrence of discontinuity in M11(a-SI_SJ) module characteristic of the open circuit $U_{O C}$ voltage (see Fig. 18b)

The discontinuity of $I-U$ characteristics, occurring in the area of open circuit $U_{O C}$ voltage (Fig. $19 \mathrm{~b}, \mathrm{c}$ ), is caused by the occurrence of cut-off $U_{\text {cut }}$, voltage, which is not stable. It is very low for large values of radiation falling on the module and increases with the decreasing radiation, i.e. with the decreasing quantity of generated $I_{p h}$ photocurrent of a PV module. And, for example, the cut-off voltage $U_{c u t}$ has the value of $0.18 \mathrm{~V}$ for illumination of the module $G_{P O A}=768 \mathrm{~W} / \mathrm{m}^{2}$ (Fig. $19 \mathrm{a}, \mathrm{b}$ ), but it achieves $7.97 \mathrm{~V}$ at the drop of illumination $G_{P O A}=8 \mathrm{~W} / \mathrm{m}^{2}$ (Fig. 19c). The occurrence of cut-off voltage $U_{c u t}$ with the value depending on the illumination level may signify the presence of numerous defects in amorphous silicon structure. These defects are called "non-linear shunts", which are 
basically due to locally extended defects leading to a local recombination current $I_{R p}$ [10]. This current creates characteristic output voltage fluctuations in the area of $U_{O C}$ (see Fig. 20).
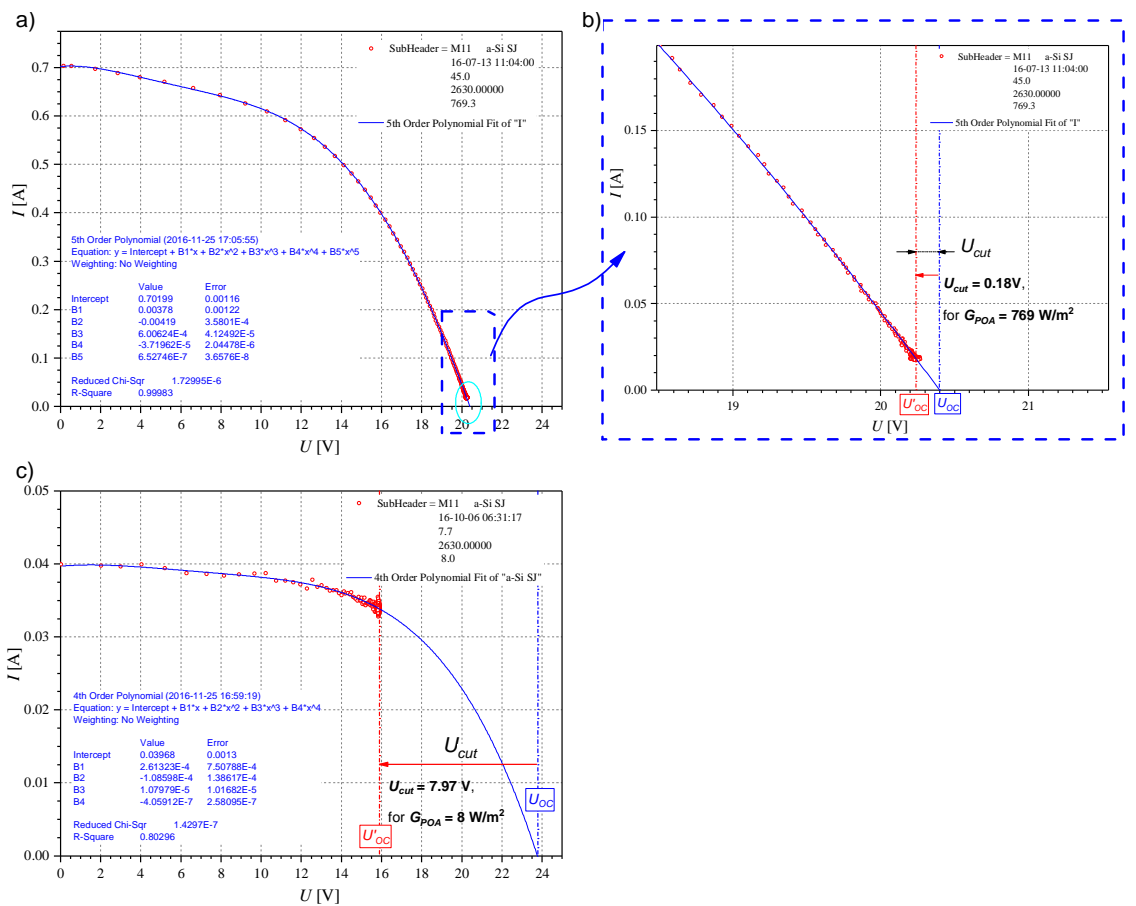

Fig. 19. The phenomenon of $I-U$ discontinuity of the M11(a-SI_SJ) module for different radiation levels: a) high $\left(G_{P O A}=769.3 \mathrm{~W} / \mathrm{m}^{2}, T_{C}=45^{\circ} \mathrm{C}\right)$ - very low value of cut-off voltage $U_{c u}$, b) zoom value of cut-off voltage $U_{\text {cut }}$ from the graph with a), and c) low $\left(G_{P O A}=8 \mathrm{~W} / \mathrm{m}^{2}, T_{C}=7.7^{\circ} \mathrm{C}\right)$ occurrence of a large value of the cut-off voltage $U_{\text {cut }}$

a)

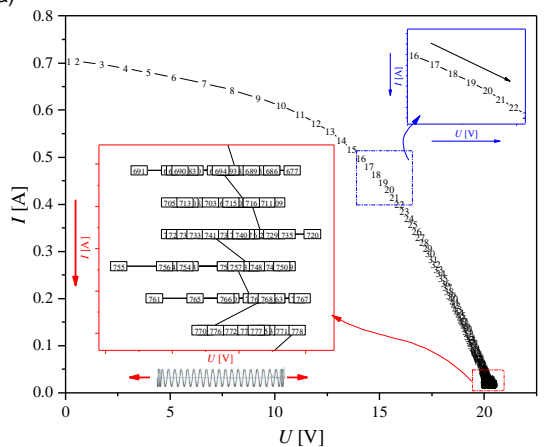

b)

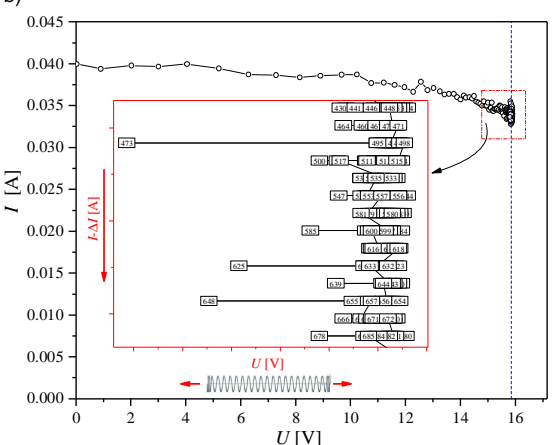

Fig. 20. The occurrence of output voltage fluctuations in M11(a-SI_SJ) module when its load is decreased, during testing: a) on a summer, hot and sunny day, i.e. 13.07.2016 at 11:04 am $\left.\left(G_{P O A}=769 \mathrm{~W} / \mathrm{m}^{2}, T_{C}=45^{\circ} \mathrm{C}\right) ; \mathrm{b}\right)$ after a hot summer, on an autumn - warm and cloudy day, i.e. 06.10 .2016 at $06: 31 \mathrm{am}\left(G_{P O A}=8 \mathrm{~W} / \mathrm{m}^{2}, T_{C}=7.7^{\circ} \mathrm{C}\right)$ 


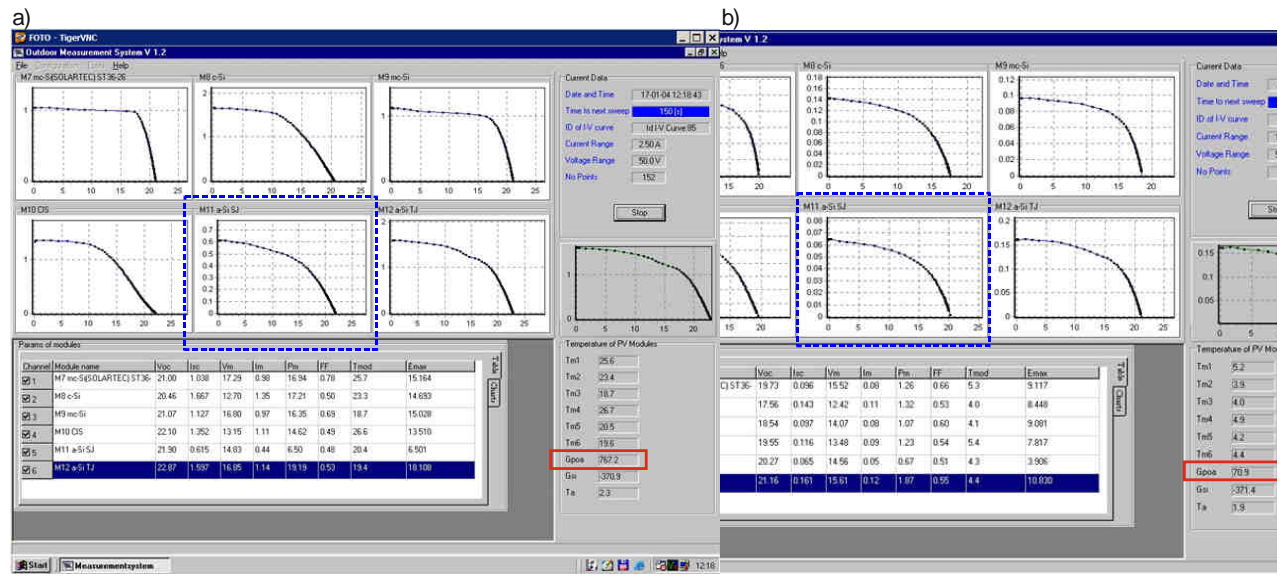

Fig. 21. The monitor screens of the PV modules testing system installed in Opole University after 15 years of exploitation, during testing on a cold winter day i.e. 4.01.2017, during illumination, i.e. at $12: 18 \mathrm{pm}\left(G_{P O A}=767 \mathrm{~W} / \mathrm{m}^{2}, T_{a m b}=2.3^{\circ} \mathrm{C}, T_{C}=20.5^{\circ} \mathrm{C}\right)$ and b) and cloudy, i.e. at 11:03 am $\left(G_{P O A}=70.9 \mathrm{~W} / \mathrm{m}^{2}, T_{a m b}=1.9^{\circ} \mathrm{C}, T_{C}=4.2^{\circ} \mathrm{C}\right)$. The lack of discontinuity in M11(a-SI_SJ) module characteristic of the open circuit $U_{O C}$ voltage (see Fig. 21b)

Figure 20 presents the occurrence of output voltage fluctuation in a PV module when its load is decreased, during testing: a) on a summer, hot and sunny day, i.e. 13.07.2016 at 11:04 am $\left(G_{P O A}=769 \mathrm{~W} / \mathrm{m}^{2}, T_{C}=45^{\circ} \mathrm{C}\right)$ and b) after a hot summer, on an autumn - warm and cloudy day, i.e. 06.11 .2016 at $06: 31 \mathrm{am}\left(G_{P O A}=8 \mathrm{~W} / \mathrm{m}^{2}, T_{C}=7.7^{\circ} \mathrm{C}\right)$. Reduction of the module load current, at constant illumination $G_{P O A}$ (i.e. at the constant value of its photocurrent $I_{p h}$ ) causes the module's voltage increase, thus activation of more non-linear shunts. In the event of a considerable decrease of the load current I, i.e. when the non-linear shunts current $I_{R p}$ becomes significant versus current $I$ (e.g. $I \leq I_{R p}$ ), the influence of nonlinear shunts current becomes visible in the form of voltage fluctuation at a PV module outlet. This phenomenon intensifies during summer - in the conditions of intense illumination and high operation temperatures of the module, in consequence with the increase of concentration of local defects in absorber; it gradually disappears during autumn-winter (see Fig. 21).

\section{Conclusions}

It is evident from the obtained results that during design stage of a photovoltaic system, apart from the knowledge of solar radiation intensity in time, it is also necessary to have more than catalogue data - parameters of photovoltaic modules. It is important to know the parameters measured not only in STC conditions, i.e. at high intensity of solar radiation $\left(1000 \mathrm{~W} / \mathrm{m}^{2}\right)$, but also at low radiation conditions. On the basis of carried out research a conclusion can be drawn that the acceptable standard parameters of a PV module (measured in STC conditions) not necessarily equal the proper "behaviour" of a module in the conditions of extremely low intensity of solar radiation. This is presented in Figures 7, 10 and 11), which present PV modules conversion efficiency, with operation characteristics from Figures 6 and 9, operating during days with extremely different insolation conditions. 
The cheap and simple method of modules' characteristics analysis presented in the article allows for providing many basic pieces of information on their operational capacity in low insolation conditions. It provides the ability to estimate usability of various modules to work in specific climate conditions. Special consideration should be given to operation in higher latitudes climatic conditions, with long periods of low insolation. The graphs of modules' operation characteristics, prepared in line with the method, which differ in power, current and output voltage - allow to make simple comparisons of their usability for dedicated operation conditions. Together with the $P V$ conversion sensitivity table, they provide valuable data for optimum selection and appropriate design of PV systems. Its preparation does not require the use of complicated measuring equipment. All the required data is registration of $U_{O C}$ and $I_{S C}$ measurement as well as a module temperature $T_{C}$. It allows to carry out early detection and assessment of the level of degradation of thin-layer modules in the monitored PV systems.

The authors hope that the above publication shall contribute to popularizing the research method as a cheap and effective method of estimating usability of modules to operate outdoors. This will allow to intensify research on optimisation of newly created cells and modules to the conditions reflecting actual climatic conditions in specified geographical regions. The research shall make producers and commercial representatives to supplement the current data of PV cells/modules with the presented graphs and certain parameters, such as, for example, $P V$ conversion sensitivity values for the selected temperatures $T_{C}$, most frequently occurring in their dedicated area of operation.

\section{References}

[1] Smith RA. Semiconductors. Cambridge: Cambridge University $\quad$ Press; 1978. https://vufind.carli.illinois.edu/all/vf-isl/Record/776963.

[2] Sze SM. Physics of Semiconductor Devices. New York: Wiley; 1981.

[3] Shockley W. The Theory of p-n Junctions and p-n Junction Transistors. In: Electrons and Holes in Semiconductors. Princeton, NJ: D. Van Nostrand; 1950.

[4] Hovel HJ. Semiconductors and Semimetals, vol. 11. New York: Academic Press; 1975.

[5] Shockley W, Read WT. Statistics of the recombination of holes and electrons. Phys Rev. 1952;87(5):835-842. DOI: 10.1103/PhysRev.87.835. https://journals.aps.org/pr/abstract/10.1103/ PhysRev.87.835.

[6] Sah CT, Noyce RN, Shockley W. Carrier generation and recombination in p-n junction and p-n junction characteristics. Proc IRE.1957;45:1228. DOI: 10.1109/JRPROC.1957.278528

[7] McIntosh K. Lumps, Humps and Bumps: Three Detrimental Effects in the Current-Voltage Curve of Silicon Solar Cells, Ph.D. Thesis. Sydney: UNSW; 2001.

[8] Milnes AG, Feucht DL. Heterojunctions and Metal-Semiconductor Junctions. New York: Academic Press, Elsevier; 1972. http://www.sciencedirect.com/science/book/9780124980501.

[9] Markvart T, Castañer L. editors. Practical Handbook of Photovoltaics. Fundamentals and Applications. Elsevier; 2003. http://www.sciencedirect.com/science/book /9781856173902\#ancPT1.

[10] Breitenstein O, Bauer J, Altermatt PP, Ramspeck K. Influence of defects on solar cell characteristics. Solid State Phenomena. 2010;156-158:1-10, http://www.scientific.net.

[11] Hussein R, Borchert D, Grabosch G, Fahrner WR. Dark I-V-T measurements and characteristics of (n) a-Si/(p) c-Si heterojunction solar cells. Solar Energy Mater Solar Cells. 2001;69:123-129. https://www.deepdyve.com/lp/elsevier/dark-i-v-t-measurements-and-characteristics-of-n-a-si-p-c-sidOAySnrsPD.

[12] Luque A, Hegedus S, editors. Handbook of Photovoltaic Science and Engineering. Chichester, England: John Wiley Sons; 2003.

[13] Breitenstein O, Altermatt P, Ramspeck K, Schenk A. The Origin of Ideality Factors > 2 of Shunts and Surfaces in the Dark I-V Curves of Si Solar Cells. Proc. $21^{\text {th }}$ Eur. Photovoltaic Solar Energy Conference and Exhibition. Dresden: 2006. http://www-old.mpi-halle.mpg.de/mpi/publi/pdf/7197_06.pdf. 
[14] Schenk A, Krumbein U. Coupled defect -level recombination: theory and application to anormalous diode characteristics. J Appl Phys. 1995;78:3185.

[15] Sah CT. Fundamentals of Solid-State Electronics. Singapore: World Scientific; 1992.

[16] Queisser HJ. Forward characteristics and efficiencies of silicon solar cells. Solid-State Electronics. 1962;5:1-10. DOI: 10.1016/0038-1101(62)90012-6.

[17] Kaminski A, Marchand JJ, Omari HEl, Laugier A, Le QN, Sarti D. Conduction Processes in Silicon Solar Cells. Proc. 25 ${ }^{\text {th }}$ IEEE PVSC. Washington DC; 1996:573-576.

[18] Breitenstein O, Heydenreich J. Non-ideal I-V-characteristics of block-cast silicon solar cells. Solid State Phenomena. 1994;37-38:139. DOI: 10.4028/www.scientific.net/SSP.37-38.139

[19] Gray JL. The Physics of the Solar Cell. Chapter 3. In: Luque A, Hegedus S. editors. Handbook of Photovoltaic Science and Engineering. Chichester, England: John Wiley Sons; 2003.

[20] Reicha N.H, van Sarka WGJHM, Alsemaa EA, Lofc RW, Schroppc REI, Sinkeb WC, et al. Crystalline silicon cell performance at low light intensities. Solar Energy Mater Solar Cells. 2009;93:1471-1481. DOI: 10.1016/j.solmat.2009.03.018

[21] Müllejans H, Hyvärinen J, Karila J, Dunlop ED. Reliability of the routine 2-diode model fitting of PV modules. Proc $19^{\text {th }}$ Europ Photovolt Solar Energy Conf. Paris 2004;2459. http://wonwoosystem.co.kr/pic/catalog/Reliability\%20of\%20Routine\%202-Diode\%20Model\%20 Fitting\%20of\%20PV\%20Modules.pdf.

[22] King DL, Boyson WE, Kratochvil JA. Photovoltaic Array Performance Model. Sandia National Laboratories Report, SAND2004-3535 Unlimited Release; 2004. http://prod.sandia.gov/techlib/ access-control.cgi/2004/043535.pdf.

[23] Yordanov GH, Midtgård OM, Saetre TO. Two-Diode Model Revisited: Parameters Extraction from Semi-Log Plots of I-V Data. $25^{\text {th }}$ European Photovoltaic Solar Energy Conference and Exhibition /5th World Conference on Photovoltaic Energy Conversion, 6-10 September 2010, Valencia, Spain: 2010; 4156. http://www.elkraft.ntnu.no/eno/Papers2010/Yordanov-EUPVSEC.pdf.

[24] Green M. Solar Cells. Operating Principles Technology and System Applications. Sydney, Australia: University of New South Wales (UNSW); 1992. https://searchworks.stanford.edu/view/1071954.

[25] Wacławek M, Rodziewicz T. Ogniwa słoneczne. Wpływ środowiska naturalnego na ich pracę. (Solar cells. The impact of the environment on their work). Warszawa: WNT; 2015.

[26] IEC 60 904-10, $2^{\text {nd }}$ edition, 2006. Methods of linearity measurement. Geneva; 2006. https://webstore.iec.ch/publication/3873, http://www.iec.ch/dyn/www/f?p=103:23:0::::FSP_ORG_ID:1276.

[27] IEC $60891,2^{\text {nd }}$ edition. Photovoltaic devices - Procedures for temperature and irradiance corrections to measured I-V characteristics. Geneva: IEC, 2009-12. https://webstore.iec.ch/publication/3821.

[28] Corrs S, Böhm M. Validation and comparison of curve correction procedures for silicon solar cells. Proc $14^{\text {th }}$ PVSEC. Barcelona: 1997;1:220-223.

[29] IEC 60 904-1. Photovoltaic Devices - Part 1: Measurement of Photovoltaic Current-Voltage Characteristics. Geneva: IEC; 1987. http://www.iec.ch/dyn/www/f?p=103:23:0::::FSP_ORG_ID:1276.

[30] Blaesser G. PV array Data Translation Procedure. Proc. 13 ${ }^{\text {th }}$ EU PVSEC. Nice: 1995.

[31] Marion B, Rummel S, Anderber A. Current-voltage translation by bilinear interpolation. Progress in Photovoltaics. 2004;12:593-607. DOI: 10.1002/pip.551.

[32] Virtuani A, Pavanello D, Friesen G. Overview of Temperature Coefficients of Different Thin Film Photovoltaic Technologies. Proc. 25 ${ }^{\text {th }}$ EU PVSEC. Valencia: 2010;4248-4252. https://www.researchgate.net/profile/Diego_Pavanello/publication/256080289_Overview_of_Temperature Coefficients_of_Different_Thin_Film_Photovoltaic_Technologies/links/557eda6d08aeb61eae260cd0/Overvi ew-of-Temperature-Coefficients-of-Different-Thin-Film-Photovoltaic-Technologies.pdf.

[33] King DL, Kratochvil JA, Boyson WE. Temperature Coefficients for PV Modules and Arrays. Measurement Methods, Difficulties, and Results. Proc. 26 ${ }^{\text {th }}$ IEEE PVSC. Anaheim: 1997. DOI: 10.1109/PVSC.1997.654300.

[34] Tsuno Y, Hishikawa Y, Kurokawa K. Temperature and Irradiance Dependence of the I-V Curves of Various Kinds of Solar Cells. Technical Digest of the PVSEC 15, Shanghai: 2005;422-423. http://www.kurochans.net/paper/15th_PVSEC/pvsec15_tsuno.pdf.

[35] IEC $60904-6,2^{\text {nd }}$ edition 2006: Requirements for reference solar modules. Geneva: 2006. http://www.iec.ch/dyn/www/f?p=103:23:0::::FSP_ORG_ID:1276.

[36] Lorenz D, Backus C. A new technique for predicting silicon solar cell short-circuit currents at reference irradiance conditions. Proc. $15^{\text {th }}$ IEEE Photovoltaic Specialist Conf. Orlando, FL: 1981.

[37] Helmke C, Jantsch M, Ossenbrink HA. An assessment of the results of calibrating 600 silicon PV reference devices. Proc. 13 ${ }^{\text {th }}$ Europ Photovoltaic Solar Energy Conf Exhibit. Nice: 1995:2319-2323. http://cordis.europa.eu/publication/rcn/199711376_es.html. 
[38] Rodziewicz T, Zaremba A, Wacławek M. Cheap sensor made of multicrystalline silicon for insolation and temperature measurements. Ecol Chem Eng S. 2016;23(4):583-591. DOI: 10.1515/eces-2016-0041.

[39] Blaesser G. The reduced current-voltage characteristic of PV arrays and its quasi-independence of ambient conditions. Proc 14 ${ }^{\text {th }}$ Europ Photovolt Solar Energy Conf. Barcelona: 1997;1520-1523. http://cordis.europa.eu/publication/rcn/199710913_en.html.

[40] Caamaño-Martín E, Lorenzo E, Lastres C. Crystalline silicon photovoltaic modules: characterization in the field of rural electrification. Prog Photovolt Res Appl. 2002;10:481-493. DOI: 10.1002/pip.436.

[41] IEC 61853-4 ED1. Photovoltaic (PV) module performance testing and energy rating - Part 4: Standard reference climatic profiles. http://www.iec.ch/dyn/www/f?p=103:23:0::::FSP_ORG_ID:1276, http://www.iec.ch/dyn/www/f?p=103:38:6878505369315::::FSP_ORG_ID,FSP_APEX_PAGE,FSP_PROJE CT_ID:1276,23,22384.

[42] IEC 1646. Thin-film terrestrial photovoltaic (PV) modules - Design qualification and type approval. http://www.iec.ch/dyn/www/f?p=103:23:0::::FSP_ORG_ID:1276.

[43] Żdanowicz T, Rodziewicz T. Wacławek M. Evaluation of actual PV modules performance in low insolation conditions. Opto-Electronics Rev. 2001;9(4):361-366. http://www.wat.edu.pl/review/optor/2001/ 4/9(4)361.pdf.

[44] Rodziewicz T, Zaremba A, Wacławek M. Technical and economic aspects of photovoltaic conversion of Southern Poland. Ecol Chem Eng S. 2014;21(2):337-351. DOI: 10.2478/eces-2014-0026. 